\title{
Robocasting of Highly Porous Ceramics Scaffolds with Hierarchized Porosity
}

\author{
Published in Additive Manufacturing $38 \mathrm{n}^{\circ} 101776$ (2021)
}

https://doi.org/10.1016/j.addma.2020.101776

\author{
L. Tabard ${ }^{\text {a }}$, V. Garnier ${ }^{\mathrm{a}}$, E. Prud'Homme ${ }^{\mathrm{a}}$, E-J. Courtial ${ }^{\mathrm{b}}$, S. Meille ${ }^{\mathrm{a}}$, \\ J. Adrien ${ }^{\text {a }}$, Y. Jorand ${ }^{\mathrm{a}}$, L. Gremillard ${ }^{\mathrm{a}, *}$
}

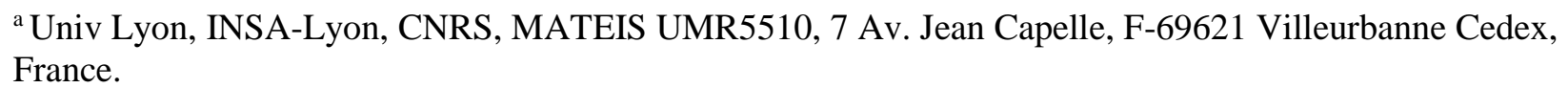

b 3d.FAB, Univ Lyon, Université Lyon1, CNRS, INSA, CPE-Lyon, ICBMS, UMR 5246, 43 Bd du 11 novembre 1918, F-69622 Villeurbanne Cedex, France.

* Corresponding author.

E-mail addresses (same order as the authors): lucie.tabard@insa-lyon.fr; Vincent.garnier@insa-lyon.fr; Elodie.prudhomme@insa-lyon.fr; edwin.courtial@univ-lyon1.fr; sylvain.meille@insa-lyon.fr; jerome.adrien@insa-lyon.fr; yves.jorand@insa-lyon.fr; Laurent.gremillard@insa-lyon.fr

\section{Keywords}

3D printing, robocasting, porous ceramics, multiscale porosity, starch

\begin{abstract}
$\underline{\text { Abstract }}$
A novel hybrid process combining robocasting and starch-consolidation method, enabling the fabrication of ceramic scaffolds with porosity as high as $85 \%$, is developed and applied to the fabrication of zirconia. This process enables a precise control of the volume and size of the porosity. It also allows its hierarchization over 4 decades of length scales and up to three porosity families: $\mathrm{i}-$ macroscopic, from $100 \mu \mathrm{m}$ to $2 \mathrm{~mm}$ and controlled by the robocasting design, ii - micronic, from $2 \mu \mathrm{m}$ to $70 \mu \mathrm{m}$ and controlled through the addition of starches as pore former in the printing past, and iii - sub-micronic, with a characteristic size of $200 \mathrm{~nm}$ and induced by a partial sintering step. The high porosity fraction and the precise control of its size distribution are above those usually found in porous ceramics fabricated with robocasting. Mechanicals properties of such porous scaffolds, investigated in compressive testing, depend both on the porous fraction and pores shape. Moreover, they are closely related to those of individual filaments produced by the same robocasting process. Thus, additive manufacturing combined with more conventional porous ceramics fabrication techniques show a big step forward for both increasing and tailoring the porosity in order to produce complex porous structures necessary for various applications in bio-medical or energy storage fields.
\end{abstract}




\section{Introduction}

Porous ceramics are now used for a wide range of different applications, where chemical and thermal stability, mechanical resistance, thermal cycling or thermal shock resistance are required [1]. Their functional properties are closely related to the amount, size, shape and connectivity of the porosity, that should be tailored with regard to the application (catalyst support [2], membrane, insulation, energy storage or biomedical being the most common ones). In the last decades, many fabrication processes have been developed to answer the specific requirements for each application. Some fabrication processes are specifically dedicated for open porosity ceramics, such a sponge replication technique and replica template technique (wood, etc.) or partial sintering technique [3] . Other fabrication techniques can result both in open or closed porosity, such as direct foaming or sacrificial fugitives technique [4].

One challenge concerning porous ceramics is to develop fabrication processes that allow a precise control in terms of distribution, size and shape of pores created, as well as their hierarchization. This would provide answers to some problematics of the century, such as finding the most efficient material to guide bone regeneration, or increasing the power or energy density in heat storage applications [5-7], the later being the main goal of the materials studied here. In this direction, new processes may open new opportunities in the fabrication of porous ceramics. For instance freezecasting technique or additive manufacturing techniques both allow the fabrication of porous ceramics with complex porous networks $[\underline{8,9]}$.

Among the various additive manufacturing techniques, robocasting (also called "direct ink writing") is quite well mastered today. Robocasting consists on the micro-extrusion of a paste in filaments shape through 50-to-2000 $\mu \mathrm{m}$ diameter needles in the three space directions [10]. Hence, it enables the fabrication of parts with extensive options in terms of materials, design of external shape and internal architecture (in particular it enables printing with multiple materials or with composition gradient [9]). Printability of the paste can be ensured by the addition of an hydrogel with suitable rheological behaviour, such as Pluronic $\AA$ F-127, to the paste formulation [11-14]. This technique is known to produce pieces with good mechanical properties compared to powder-based additive manufacturing techniques, thanks to a process with minimum number of steps and of organic additives [15]. As with most other additive manufacturing techniques, macro-scale design can be easily modulated by modification of the CAD files used as numeric models. Robocasting enables the control of macroscopic porosity, above $50 \mu \mathrm{m}$, by tailoring the design and the printing parameters. However the control of the porosity below $50 \mu \mathrm{m}$, and especially below the filament scale, is usually limited, even if necessary for some applications. In fact, porous materials with complex shapes such as bone fillers or dental implants require different scales of interconnected porosity, from nanometric to micrometric sizes. It is also the case of bio-inspired ceramics used to mimic tooth enamel or nacre, that show a specific orientation of their microstructure to arrest crack propagation [16]. Ceramics for filtering and membrane applications, as well as those inspired by bamboos show highly porous, organized microstructures, that are lightweight but with great mechanical properties[17]. In such cases, open and interconnected porosity at different scales is required, from the macroscopic level up to the nanoscopic level, which adds some complexity in the processing. Hybrid processes using a multiscale approach could answer to such specifications.

Such hybrid processes already exist based on additive manufacturing techniques. For example, it is possible to combine robocasting process with direct foaming or emulsion methods to increase the porosity at filament scale $[\underline{18,19]}$. One can also combine robocasting process with freeze-casting to tailor the microstructure of the printed scaffolds [20]. Porous ceramics of any shape can also be fabricated by combining additive manufacturing with replication technique [21].

Robocasting was not yet used in combination with sacrificial fugitive technique. Among the numerous fugitive phases that can be used to fabricate porous ceramics, starches present several advantages. First, porosity obtained with addition of sacrificial fugitives is close in size and shape to the original sacrificial fugitives added. Depending on their origin, starches sizes can vary from 2 to 
$170 \mu \mathrm{m}$, enabling to target a wide range of porosity size. In addition, starches of different nature and size can be mixed together depending on the level of complexity required for the application [22]. Moreover, starches are easily burned out, are agricultural by-products and are therefore very cheap and bio-sourced $[23,24]$. In addition, starches seem to be great candidates as fugitive phase for robocasting technique, thanks to their gelling ability due to absorption of water at around $55-80{ }^{\circ} \mathrm{C}$, depending on the starch type, that can help in the robocasting process [22,25]. Besides, if needed it is possible to create interconnected porosity using starch with a minimum ratio of $60 \mathrm{vol} . \%$ versus the volume of ceramic powder [16].

In this study, we seek to address the question of the hierarchization of the porosity, with at least three different scales (macroscopic, filament and ceramic grain size). A versatile system composed of a ceramic paste containing a fugitive phase, printed by robocasting and partially sintered is proposed to answer this requirement. This article shows the results obtained by robocasting a ceria-toughened zirconia-based paste containing different amounts of starches of various origins.

The fabrication process developed here allows the fabrication of hierarchized porous scaffolds with three different levels of porosity that can be easily modulated. Macroscopic channels composing the scaffold control the first level of porosity. Then, at filament scale, the addition of starches as fugitives phase controls the second level of porosity, at micronic scale. Finally, a partial sintering step allows the control of a third level of sub-micronic porosity.

Our global strategy was to fabricate a model scaffold design, assuming that the design can be easily modified depending on the application. The effects of the addition and combination of starches from various origin to a printable zirconia-based paste were evaluated, by rheometry at the paste preparation step and by microstructural analysis at the scaffold step. For all compositions, the different porous networks were thoroughly characterized by complementary methods in terms of quantity, size, shape and distribution of the pores. Mechanical properties were also investigated on single filaments and on scaffolds.

\section{Materials and methods}

\subsection{Materials}

Ceria-stabilized zirconia powder (CEZ-12, $0.5 \mu \mathrm{m}$ particle size, Daiichi Kigenso Kagaku Kogyo Co. Ltd, Osaka, Japan) was used as ceramic. Pluronic ® F-127 (Sigma-Aldrich), referred to as PF127, in solution in $18 \mathrm{M} \Omega$ DI water was used as a carrier to ensure the good printability of the paste. DARVAN 821A (R.T. Vanderbilt, Norwalk, CT) was used as a dispersant for the ceramic powder. Wheat starch, potato starch and rice starch (Fisher chemical, extra pure) were used as sacrificial fugitives. Particle size (equivalent diameter) distribution in number was evaluated on each starch type for 300 particles with optical microscopy (Axiophot, ZEISS, Gemany) at a $\times 250$ magnification. The average diameters were evaluated by fitting a cumulative lognormal distribution to the particle size distribution.

\subsection{Paste formulation and characterization}

Printing pastes were all prepared with a common protocol. First, a water-based solution of PF127 at 25 wt. \% (25 g PF127 in 75 g DI water) was prepared. Then, zirconia and starches powders were dispersed in the PF127 solution with DARVAN 821A as dispersing agent. For pastes without starch, 0.75 wt. \% of dispersant (with reference to the zirconia weight) was necessary to achieve adequate dispersion. For pastes with starches the amount of dispersant could be decreased to $0.5 \mathrm{wt}$. $\%$ of the zirconia weight. This decrease in the necessary quantity of dispersant may be attributed to two causes. First, the bimodal particle size distribution (PSD) achieved in the presence of starch(es) with $\mathrm{ZrO}_{2}$ should decrease the viscosity of suspensions as compared to monomodal PSD, an effect widely discussed in the literature (see for instance [26,27]). Second, as starches are partially soluble in water at $25^{\circ} \mathrm{C}$ (up to $4 \%$ for potato starch, counting soluble molecules and highly swollen particles[28,29]), 
an additional steric dispersion effect might be due to the adsorption of the soluble molecules (chains constituted of glucose units) on the zirconia particles (since we have no direct proof that this adsorption takes place, this is only an hypothesis).

Both zirconia and starches powders were gradually added in the mixture and homogenized after each addition in a planetary mixer (SpeedMixer, Synergy devices limited) at $1800 \mathrm{rpm}$. During mixing the pastes were periodically cooled in an ice bath so that the PF127 solution stayed in its liquid state to ease the dispersion of the particles. Table 1 sums up the different as-prepared compositions. Paste with zirconia only will be referred to as Z; paste with zirconia and wheat starch as ZW; paste with zirconia, wheat and rice starches as ZWR; paste with zirconia, potato and rice starches as ZPR.

\begin{tabular}{|c|c|c|c|c|c|}
\hline Name & Starch nature & $\begin{array}{l}\text { Starch } \\
(\text { vol \%) }\end{array}$ & $\begin{array}{c}\text { Zirconia } \\
(\text { vol\%) }\end{array}$ & $\begin{array}{c}\text { starch /zirconia } \\
\text { volume ratio }\end{array}$ & $\begin{array}{c}\text { Total dry } \\
\text { amount } \\
(\text { vol\%) } \\
\end{array}$ \\
\hline Zirconia (Z) & none & 0 & 36 & 0 & 36 \\
\hline $\begin{array}{c}\text { Zirconia + wheat } \\
(\mathrm{ZW})\end{array}$ & wheat & 24 & 12 & $2 / 1$ & 36 \\
\hline $\begin{array}{c}\text { Zirconia }+ \text { wheat }+ \\
\text { rice } \\
(\mathrm{ZWR})\end{array}$ & wheat and rice & $\begin{array}{c}24 \\
(12 \mathrm{~W}+12 \mathrm{R})\end{array}$ & 12 & $2 / 1$ & 36 \\
\hline $\begin{array}{l}\text { Zirconia }+ \text { potato }+ \\
\text { rice }(Z P R)\end{array}$ & Potato and rice & $24(12 \mathrm{P}+12 \mathrm{R})$ & 12 & $2 / 1$ & 36 \\
\hline
\end{tabular}

Table 1: Composition of each fabricated paste.

The maximum solid loading of our inks is $36 \mathrm{vol} . \%$ of zirconia with the objective to print porous filaments. Other approaches using dispersant-binder-coagulant system could lead to higher solid loading (up to $48 \%[30,31]$ ) to prepare inks for extrusion of dense filaments. Indeed, higher solid loading with high enough elastic moduli to the inks for shape retention and a selection of appropriate processing additives for adapted rheological behavior will affect the quality of green body and consequent mechanical properties and reliability of the 3D printed scaffolds [32-35]. Alternatives for higher solid loading inks exist and could deserve to be explore even for printing porous filaments." To evaluate the printability of the pastes $[\underline{36,37]}$, rheological measurement were conducted with a stress controlled rheometer Discovery HR-2 (TA instrument, USA), using a plane-plane geometry of $40 \mathrm{~mm}$ in diameter and a humidity trap to avoid the drying of the pastes during measurements. Rheological measurements of PF127 alone were also conducted, in the same conditions, to evaluate the influence of solid loads (zirconia and starch) in the pastes. To make sure of the relevance of the results, prior to all oscillatory measurements the linear viscoelastic regime was determined for each composition using the dynamic oscillation approach at a $10 \mathrm{rad} \cdot \mathrm{s}^{-1}$ angular frequency [38].

First, the rheological behaviour of the pastes were determined by following $\tan \delta$, a dimensionless parameter equal to the loss to storage moduli ratio $\left(\mathrm{G}^{\prime}, \mathrm{G}^{\prime}\right)$, as a function of angular frequency $\omega$ in oscillatory sweep mode. The aim of this test was to make sure that the pastes behave as solid-like materials, characterized with a $\tan \delta<1$. From this same test, the shear-thinning behaviour of pastes was characterized by the evolution of complex viscosity:

$\eta^{*}=\frac{\sqrt{G^{\prime 2}+G \prime^{\prime 2}}}{\omega}$

as a function of angular frequency.

Then, the static yield stress $\left(\tau_{\mathrm{y}}^{\mathrm{s}}\right)$ value was determined from a stress ramp method. In this test, the static yield stress value corresponds to the maximum viscosity point in the viscosity/stress curve. Indeed up to the yield stress the material presents an elastic behaviour. The yield stress itself corresponds to a break-down of the elastic structure, thus to the initiation of the flow, leading to a rapid increase in shear rate and a large decrease in viscosity. The static yield stress value will help conclude on the printability of each paste [ㅌ6]. 
Storage modulus ( $\left.\mathrm{G}^{\prime}\right)$ evolution with time was measured at $1 \mathrm{rad} \cdot \mathrm{s}^{-1}$, after a very moderate pre-shear treatment $\left(3 \mathrm{~s}^{-1}\right.$ for $\left.10 \mathrm{~s}\right)$. In these conditions they are believed to be representative of the storage modulus at near-rest, i.e. after deposition.

Finally measurement of the self-healing time of ZW paste was conducted in three steps, all in oscillatory conditions at $1 \mathrm{~Hz}$ : first step is the measurement of $G^{\prime}$ and $G$ ' at near rest (maximum strain $0.03 \%$ ) during 120s; second step is a large destructuration (maximum strain 1000\%) during $130 \mathrm{~s}$; last step is again the measurement of G' and G' at near rest during 600s, and is performed to assess the self-healing time of the paste after destructuration.

\subsection{Printing process}

Parts were printed at $23{ }^{\circ} \mathrm{C}$, in the gel temperature domain of the PF127, ensuring the shear thinning behaviour necessary for printing. During printing the relative humidity $(\mathrm{RH})$ was set to $98 \%$ to prevent tip clogging and premature drying of the printed parts. Printing of the pastes was performed with a Robocasting device (3D-Inks, Tulsa, OK, USA), with tips of $410 \mu \mathrm{m}$ inner diameter (Nordson EFD, USA). An interpenetration of $15 \%$ of the tip diameter between two layers (thus a layer-to-later distance of $349 \mu \mathrm{m}$ ) ensured the cohesion between successive layers. Parts were all printed with the same design, as porous scaffolds of $10 \times 10 \times 5 \mathrm{~mm}^{3}$ or $10 \times 10 \times 10 \mathrm{~mm}^{3}$, with $90^{\circ}$ disorientation between successive layers and a $390 \mu \mathrm{m}$ hollow space between two filaments in a same layer (corresponding to a center-to-center distance of $800 \mu \mathrm{m}$ ).

The printing substrate was composed of a flat glass plate covered with a smooth polymer sheet (copier polyester transparency film). In order to optimize the robustness of the process and to minimize strain during drying of the pieces the polymer sheet was covered by a thin coating composed of a first layer of Teflon grease and a second layer of coconut oil coating (mainly composed of lauric (dodecanoic), oleic ((9Z)-octadec-9-enoic) and myristic (1-tetradecanoic) acids).

\subsection{Post-processing}

After printing, in order to remove water without inducing cracks, the scaffolds were slowly dried in a climatic chamber (WKL 150, Weiss Technik, France) with controlled atmosphere, with conditions changing gradually from $98 \% \mathrm{RH}$ at $24{ }^{\circ} \mathrm{C}$ to $30 \% \mathrm{RH}$ at $60{ }^{\circ} \mathrm{C}$ over four days. Then, starches and organic additives were removed during a stepwise debinding stage to avoid cracking of the samples $\left(0.5{ }^{\circ} \mathrm{C} \mathrm{min}{ }^{-1}\right.$ up to $350{ }^{\circ} \mathrm{C}$ to eliminate the PF127, $2{ }^{\circ} \mathrm{C} \mathrm{min}-1$ up to $600{ }^{\circ} \mathrm{C}$ and a dwell of 2 hours at $600{ }^{\circ} \mathrm{C}$ to burn out the remaining starches). Finally, samples were partially densified using a partial sintering cycle inducing the growth of necks between ceramic particles with almost no densification [39], thus maintaining a large porosity within the struts with reasonable mechanical properties $\left(5{ }^{\circ} \mathrm{C} \min ^{-1}\right.$ up to $800{ }^{\circ} \mathrm{C} ; 3{ }^{\circ} \mathrm{C} \min ^{-1}$ up to $1000{ }^{\circ} \mathrm{C} ; 1^{\circ} \mathrm{C} \mathrm{min}{ }^{-1}$ up to $1250{ }^{\circ} \mathrm{C}$ and a dwell of two hours at $\left.1250{ }^{\circ} \mathrm{C}\right)$.

\subsection{Materials characterization}

Fabricated pieces were systematically weighted with a precision balance $(0,001 \mathrm{~g})$ and measured with a caliper gauge to calculate their apparent density. Five samples of each composition were prepared and measured.

Scanning Electron Microscopy (SEM) observations in secondary electron mode were conducted to characterize the microstructure of each fabricated porous scaffold (using a Zeiss SUPRA-45 SEM, at $2 \mathrm{kV}$ and a working distance of $2 \mathrm{~mm}$ ). The sub-micronic porous ratio left by partial sintering was measured by image analysis, using Fiji software with the thresholding tool, on 30 images. This ratio was considered to be the same in $2 \mathrm{D}$ and in $3 \mathrm{D}$ thanks to the cylindrical capillary shape of the submicronic porosity. 
X-ray tomography at two different resolutions was used to characterize both the macroscopic structure of the parts and their microstructure. Macrostructure was analysed using a voxel size of $7 \mu \mathrm{m}$ to check the lack of cracks and defects (using a GE Sensing \& Inspection technologies Phoenix $\mathrm{x}$ |ray v|tome|x s tomograph). Local X-ray tomography at a voxel size of $0.3 \mu \mathrm{m}$ was performed to characterize the 3-dimensionnal porous networks created by (using a RX Solutions EasyTom Nano tomograph equipped with a Hamamatsu tube). 3D-image analysis (using Fiji software) was used to analyse the raw data. The analysing tool "local thickness" was used to measure the printed filaments diameter on the whole sample volume [40,41]. The macro and micro-porous ratio of the parts were measured with the thresholding tool, on 300 slices. The plugins "labelling 3D" (used to detect and label 3D clusters of connected voxels, using the 26 closest neighbours) and "param 3D" (used to calculate morphology parameters such as volumes), developed by MATEIS, were used to measure the interconnection ratio of the micro-porous network [42], quantified as the [largest porosity volume] / [total porosity volume] ratio.

Mercury intrusion porosimetry (Autopore V, Micromeritics) was used to quantify the porous volume and the pore access diameter distribution (for pore access diameters between $4 \mathrm{~nm}$ and $300 \mu \mathrm{m}$ ). The results were corrected with the built-in blank correction formula. The incremental intrusion vs pore size curves were deconvoluted with lognormal distributions to analyse the characteristics (mean access size, volume) of each population of pores separately. The first steps in the cumulative intrusion curves correspond to a part of the macro-porosity created by the design of the scaffold and were not considered here (because they do not show the whole macro-porosity): only the micronic and submicronic porosities were measured on those curves. Figure 1 summarizes the techniques used to assess porosity and their measurement range.

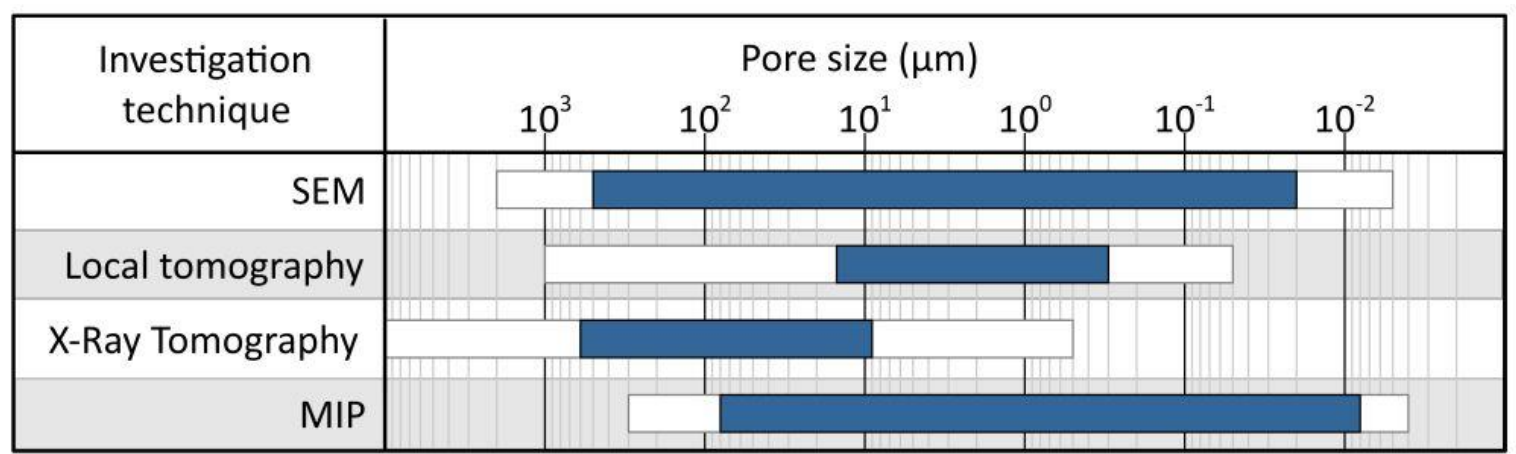

Figure 1: Overview of the techniques used to quantify the entire range of pores contained in the parts. The shaded areas correspond to the optimal analyses ranges of the considered techniques, used in the present study.

The mechanical properties were determined using two complementary tests: compressive tests on $1 \mathrm{~cm}^{3}$ scaffolds ( 5 scaffolds of each composition) and 3 points bending tests on printed filaments ( 5 filaments of each composition) to characterize their intrinsic properties. Compressive tests were performed with an Instron electro-mechanic universal testing machine (Instron 8500+, Elancourt, France) equipped with a $5 \mathrm{kN}$ load cell, at $0.033 \mathrm{~mm} \mathrm{~s}^{-1}$ crosshead speed. A parafilm layer was deposited on the upper and lower surfaces of the scaffolds to ensure their flatness and control the contact conditions, hence minimizing compressive uncertainties. A pre-load of $1 \mathrm{~N}$ was applied to minimize the influence of the parafilm deformation on the load-displacement curves. Results obtained as load-crosshead displacement curves were then converted in stress $\left(\sigma_{c}\right) /$ strain $\left(\varepsilon_{c}\right)$ curves using the apparent section of each sample $\left(\sim 1 \mathrm{~cm}^{2}\right) .3$ points bending tests were conducted with a Bose ElectroForce ${ }^{\circledR} 3200$ (Prairie Valley, USA) equipped with a $20 \mathrm{~N}$ load cell, at $0.01 \mathrm{~mm} \mathrm{~s}^{-1}$ crosshead speed. To help with the filaments handling, filaments were printed with a larger printing tip $(800 \mu \mathrm{m})$. To avoid the flattening of the extruded filament after printing, filaments were extruded vertically in the air before being slowly deposited on the printing substrate. Therefore, the filaments were 
assimilated to perfect cylinders (variation of diameter of $2 \%$ ) and the maximum tensile stress $\left(\sigma_{b}\right)$ and Young's modulus (E) were calculated with the following equation:

$$
\begin{aligned}
& \sigma_{b}=\frac{8 F L}{\pi d^{3}} \\
& E=\frac{4 L^{3}}{3 \pi d^{4}} \frac{\delta F}{\delta u}
\end{aligned}
$$

where $\mathrm{F}$ is the applied load at fracture, $\mathrm{L}$ is the distance between the lower supports, $\mathrm{d}$ is the filaments diameter, $\mathrm{u}$ is the displacement (assimilated to the crosshead travel) and $\delta \mathrm{F} / \delta \mathrm{u}$ is the slope of the load/displacement curve.

\section{Results}

\subsection{Starches sizes}

Figure 2 shows the particle size number distribution of the different starches. The potato, wheat and rice starches particles show respective average diameters ( \pm standard deviation) of $27 \pm 17 \mu \mathrm{m}, 13 \pm$ $6 \mu \mathrm{m}$ and $3 \pm 1 \mu \mathrm{m}$.

\subsection{Rheological behaviour}

Figure 3(a) shows a solid-like behaviour $(\tan \delta<1)$ for all pastes, hence, they can be assimilated to a tri-dimensional network. The evolution of the complex viscosity (Figure 3(b)) shows that this network tends to be destroyed and to flow with increasing frequency, with a shear-thinning behaviour (with pseudo-plasticity indices between 0.9 and 0.95). The addition of solid loads (ceramic particles and starch) in the tri-dimensional network results in an increase in the complex viscosity values by two or three decades (at $1 \mathrm{rad} \mathrm{s}^{-1}$, from $8.7 \mathrm{kPa}$ s for PF127 (Section 2.1) formulation to $2.2 \mathrm{MPa}$ for zirconia alone $(\mathrm{Z})$ formulation). Furthermore, complex viscosity values are higher for the paste without starch compared to all pastes with starches (at $1 \mathrm{rad} \mathrm{s}^{-1}, \eta^{*}{ }_{[\mathrm{ZW}]}=0.3 \mathrm{MPa} \mathrm{s}<\eta^{*}[\mathrm{ZWR}]=$ $0.4 \mathrm{MPa} \mathrm{s}<\eta^{*}{ }_{[\mathrm{ZPR}]}=0.5 \mathrm{MPa} \mathrm{s}<\eta^{*}{ }_{[\mathrm{Z}]}=1.2 \mathrm{MPa}$ s). Figure 3(c) shows a yield stress behaviour for all pastes. The PF127 formulation has the smaller value (900 Pa) and $\mathrm{Z}$ the higher value (3000 Pa). Other formulations present static yield stress values from 900 to $1000 \mathrm{~Pa}$, close to PF127 formulation. Figure 3(d) shows that all pastes show very stable storage moduli at near rest for at least $900 \mathrm{~s}$ after recovery from a moderate destructuration $\left(3 \mathrm{~s}^{-1}\right)$, with storage moduli close to $2 \cdot 10^{5} \mathrm{~Pa}, 4 \cdot 10^{5} \mathrm{~Pa}$, $5 \cdot 10^{5} \mathrm{~Pa}$ and $10^{6} \mathrm{~Pa}$ (for ZW, ZWR, ZPR and Z respectively). PF127 hydrogel presents a much lower storage modulus $\left(\mathrm{G}^{\prime}=10^{4} \mathrm{~Pa}\right)$. The measurement of the self-healing time was performed only on the paste with the lowest storage moduli $(\mathrm{ZW})$, and is shown in Figure 3(e,f,g). After complete destructuration $(1000 \%$ strain at $1 \mathrm{~Hz})$ the storage moduli drops first at $100 \mathrm{~Pa}$; when destructuration stops and $\mathrm{G}^{\prime}$ is measured at near rest condition $(0.03 \%$ strain at $1 \mathrm{~Hz}), \mathrm{G}^{\prime}$ increases in less than $18 \mathrm{~s}$ to $\sim 2 \cdot 10^{5} \mathrm{~Pa}$, plateau value similar to the one observed in Figure $3(\mathrm{~d})$ for a more moderate destructuration.

\subsection{Microstructure}

\subsubsection{SEM characterization}

Figure 4(a,e,i,m) show the printed parts after sintering. SEM observations show the different porous networks at different scales: Figure $4(b, f, j, n)$ show macro-porosity at around $250 \mu \mathrm{m}$. Figure $4(\mathrm{c}, \mathrm{g}, \mathrm{k}, \mathrm{o})$ show micronic porosity left by starches from $2 \mu \mathrm{m}$ to $70 \mu \mathrm{m}$ and Figure $4(\mathrm{~d}, \mathrm{~h}, \mathrm{l}, \mathrm{p})$ show both the micronic porosity and the sub-micronic porosity due to the partial sintering, of size around $200 \mathrm{~nm}$. Figure 4(b) reveals the presence of cracks for composition $\mathrm{Z}$, at the crossroads between 
layers; no cracks are noticed for compositions with addition of starches. In all cases, pores left by starches are homogeneously distributed, and they show different sizes respective of the starch sizes. Moreover, micrographs with the highest resolution reveal tortuous micronic pore shapes, mainly for wheat and rice starches. Finally, partial sintering of the zirconia looks homogeneous through the filament section. Figure 4(b,f,j,n) shows that the filaments are not completely straight, showing that they can deform slightly under their own weight before drying. We draw the attention of the reader on the fact that characteristic dimensions of the architectures (interlayer distance, filaments diameter, filament to filament distance...) should not be derived from these SEM observations, since the relative orientation of the printing directions and observation direction are not well known.

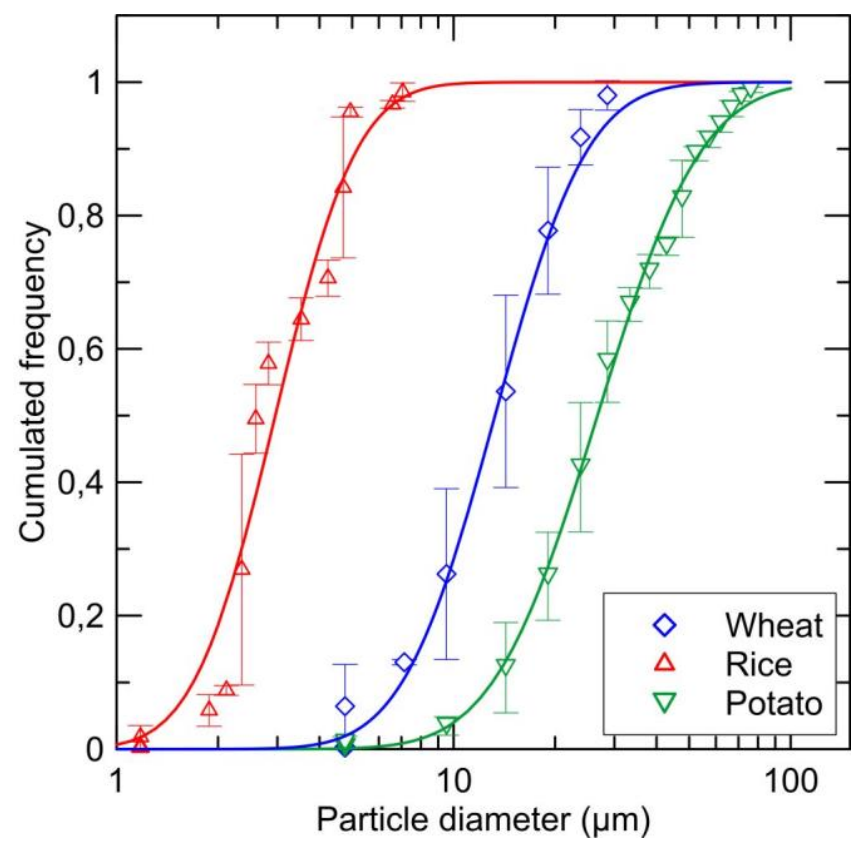

Figure 2: Particle size number distribution of rice starch, wheat starch and potato starch. Each point represent the average cumulative frequency on a given diameter class, the error bars representing the minimum and maximum cumulative frequencies associated to the same class. The continuous lines are fits by cumulative lognormal distribution. 

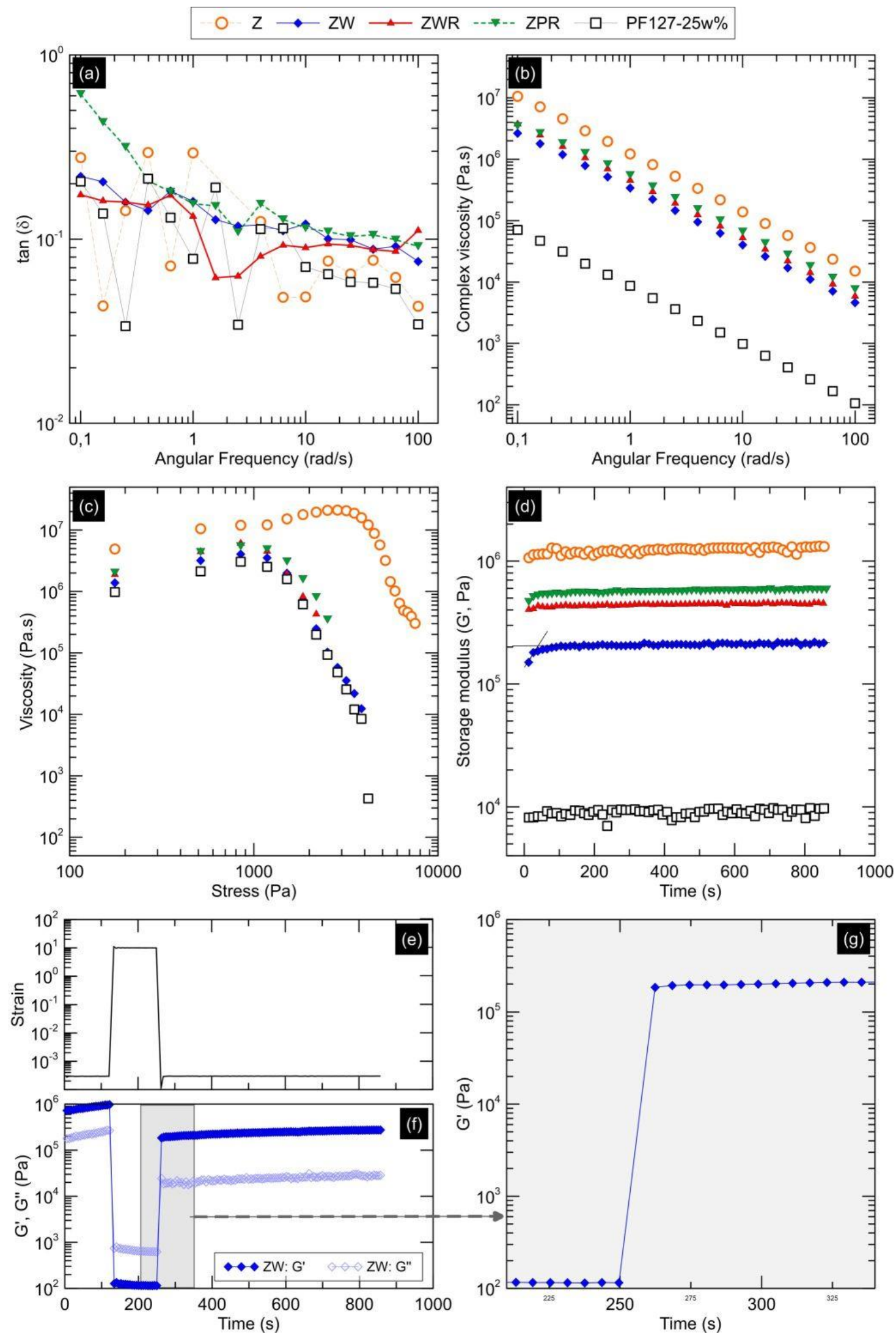

Figure 3: Rheological properties of pastes. (a) Solid-like behaviour: $\tan (\delta)$ vs angular frequency (frequency sweep mode); (b) Shear thinning behaviour: complex viscosity vs angular frequency (frequency sweep mode); (c) Yield stress behaviour: Viscosity vs Stress (stress ramp mode). (d) Storage modulus stability: Storage modulus vs Time (after a slight pre-shear treatment and at constant angular frequency). (e) Strain profile and $(f)$ storage and loss modulus of ZW during the self-healing time measurement; $(g)$ is a zoom of $(f)$ on the second transition (grey rectangle). All tests were performed at room temperature $\left(25^{\circ} \mathrm{C}\right.$ ) with humidity trap to avoid the drying of the pastes during measurements. 


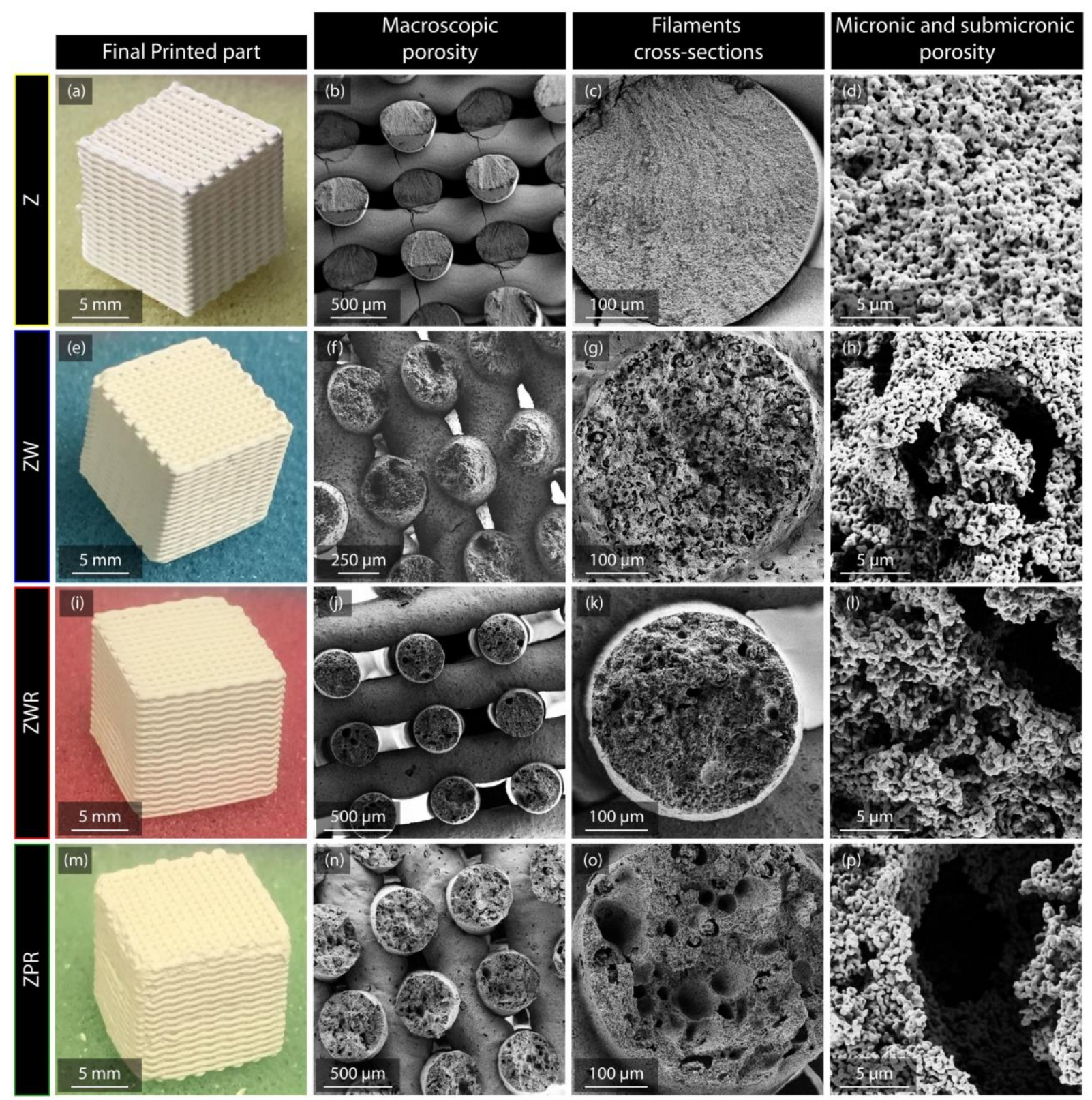

Figure 4: $(a, e, i, m)$ : Final printed parts; SEM views of the parts at different magnifications: $(b, f, j, m)$ macroscopic porosity and architecture of the parts; $(c, g, k, 0)$ cross-sections of the filaments; $(d, h, f, p)$ view of the micronic and sub-micronic porosity on filaments cross-ections.

\subsubsection{Tomography characterization}

X-ray tomography scans (Figure 5) show that ZW and ZWR materials are crack-free, whereas ZPR shows one long crack in the middle of the piece (Figure 5(d)), which seems to be the result of an isolated defect. In opposition, numerous small cracks are noticed at the crossroads between layers for the reference composition with no starch Z (indicated by the arrows on Figure 5(a)). Macroporous fraction due to the design as determined by 3D image analysis is shown in Table 2.

The distributions of filament diameters are shown in Figure 6, and are not the same for all compositions (also visible in Figure $4(b, f, j, n)$, even though the same numeric model and needle diameter $(410 \mu \mathrm{m})$ were used for the printing of all compositions. For all compositions, measurements of diameters smaller than $300 \mu \mathrm{m}$ correspond to crossroad of filaments between two layers. For composition with zirconia only, the mean filament diameter is $390 \mu \mathrm{m}$. However, for parts with addition of starch, mean diameters are respectively 430, 460 and $480 \mu \mathrm{m}$ for ZW, ZWR and ZPR. The results are consistent with the lower macro-porous ratio measured by image analysis on tomography scans (Table 2). 

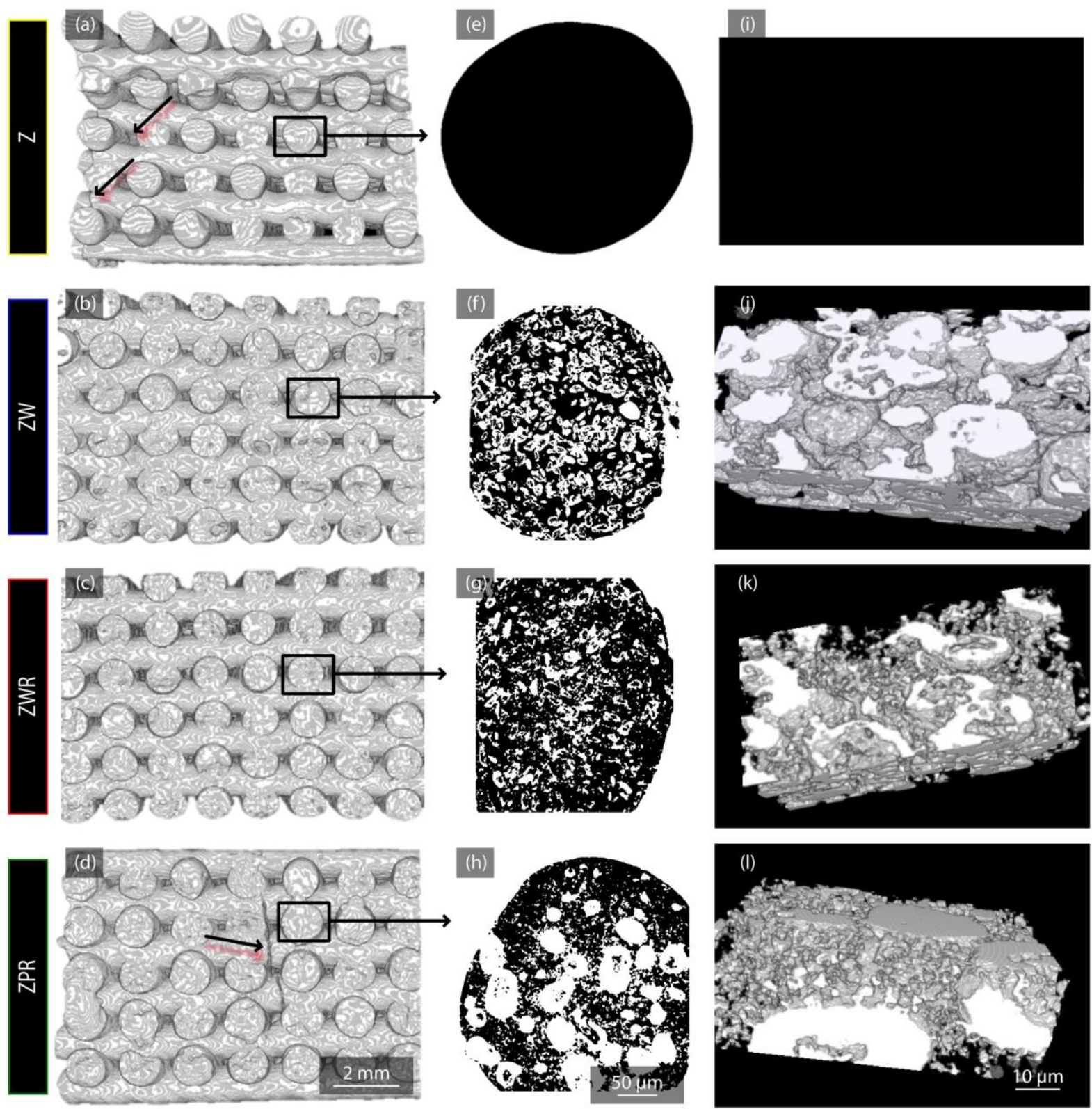

Figure 5: Tomographic analysis of fabricated pieces: (a-d): perspective views of macroscopic volumic reconstruction (7 $\mu \mathrm{m}$ voxel size); (e-h): thresholded images (slices) of filaments with pores shown in white (0.3 $\mu \mathrm{m}$ voxel size); (i-l): perspective views of microscopic volume reconstruction $(0.3 \mu \mathrm{m}$ voxel size), with the printing direction from the left to the right of the figures. Arrows in (a) and (d) point to cracks. In (e) and (i) (material Z), no porosity is visible at this scale of observation, explaining the completely black reconstructions of the porosity. Scale bars in (a-d) and (i-I) are only indicative since these figures are 3D reconstructions shown in perspective.

$\mathrm{X}$-ray micro-tomography at voxel size of $0.3 \mu \mathrm{m}$ enables the volumetric reconstruction of porous networks created by starches, as can be seen in Figure 5(e-h) (in which porosity is shown in white). Sizes of rice starches are at the limit of resolution due to their small sizes, thus their quantification is less precise than the ones of wheat and potato starches. Some air bubbles, differentiated from the pores left by the starches by their round shape, are detected at this resolution, especially for paste with potato starches, but their total volume fraction is negligible compared to porosity created by starches. Interconnectivity of more than $98 \%$ of the micronic porosity was measured for all compositions with starches. Moreover, pores are elongated in the printing direction for all compositions (Figure 5(i-1)). 

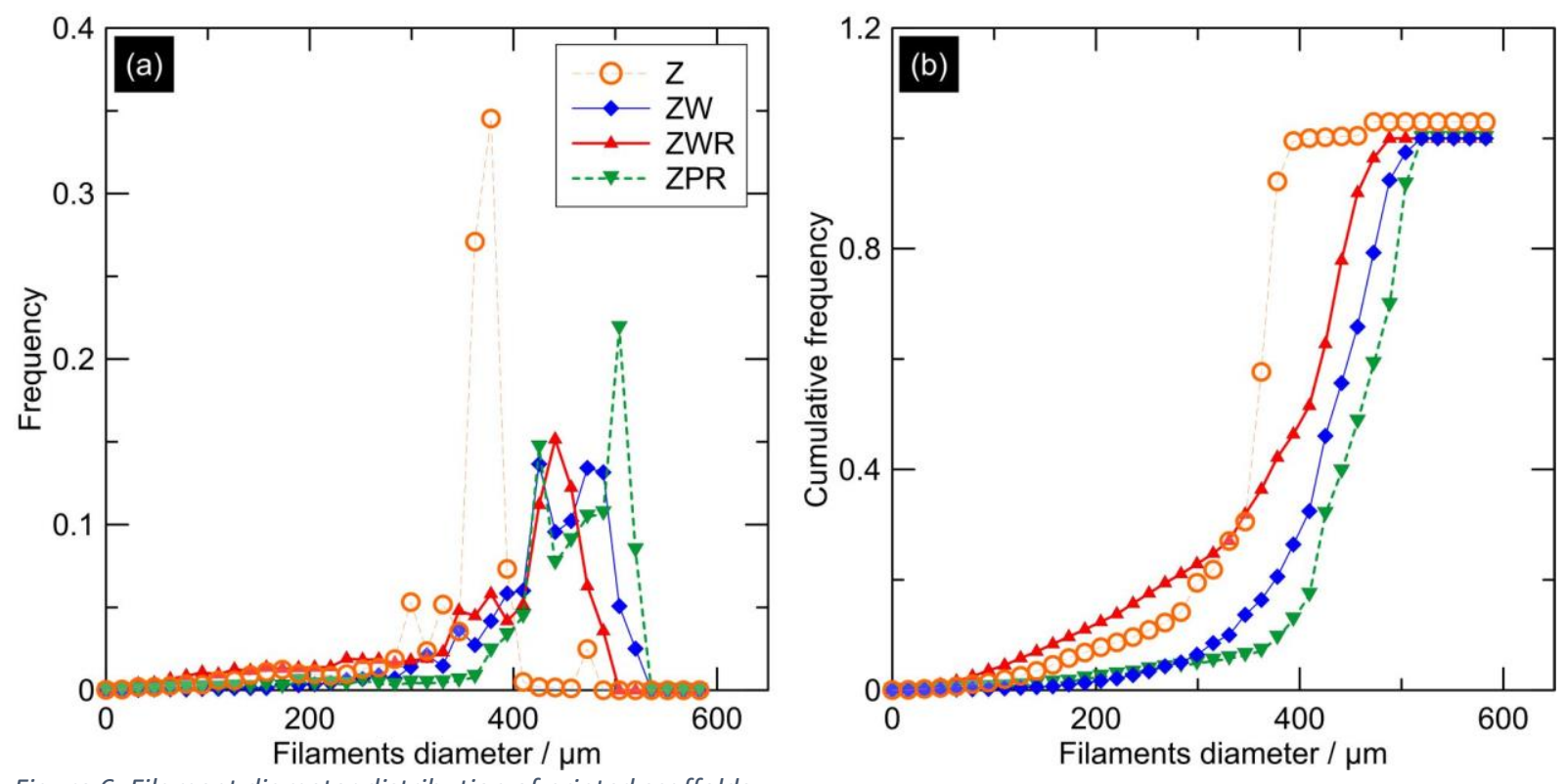

Figure 6: Filament diameter distribution of printed scaffolds.

\subsubsection{Pores characterization}

Quantity and channel sizes of micronic and sub-micronic pores were measured with mercury intrusion porosimetry (MIP). As shown on Figure 7, only the contribution of pores of sizes below $80 \mu \mathrm{m}$, left by starches and partial sintering, were considered. Above $80 \mu \mathrm{m}$, the porosity was not measured, as explained in the materials and methods section. The cumulative intrusion curves show the intruded mercury volume $v s$ decreasing pore access diameter, i.e. increasing pressure. Each steep increase in these curves reveals a family of pores. Knowing the average particle size of each family of starch at the origin of the pores, it is possible to assign each lognormal distribution to a type of starch or to partial sintering, therefore the log-differential intrusion $v s$ diameter curves were fitted by 2 or 3 lognormal distributions (depending on how many pore size families were expected).
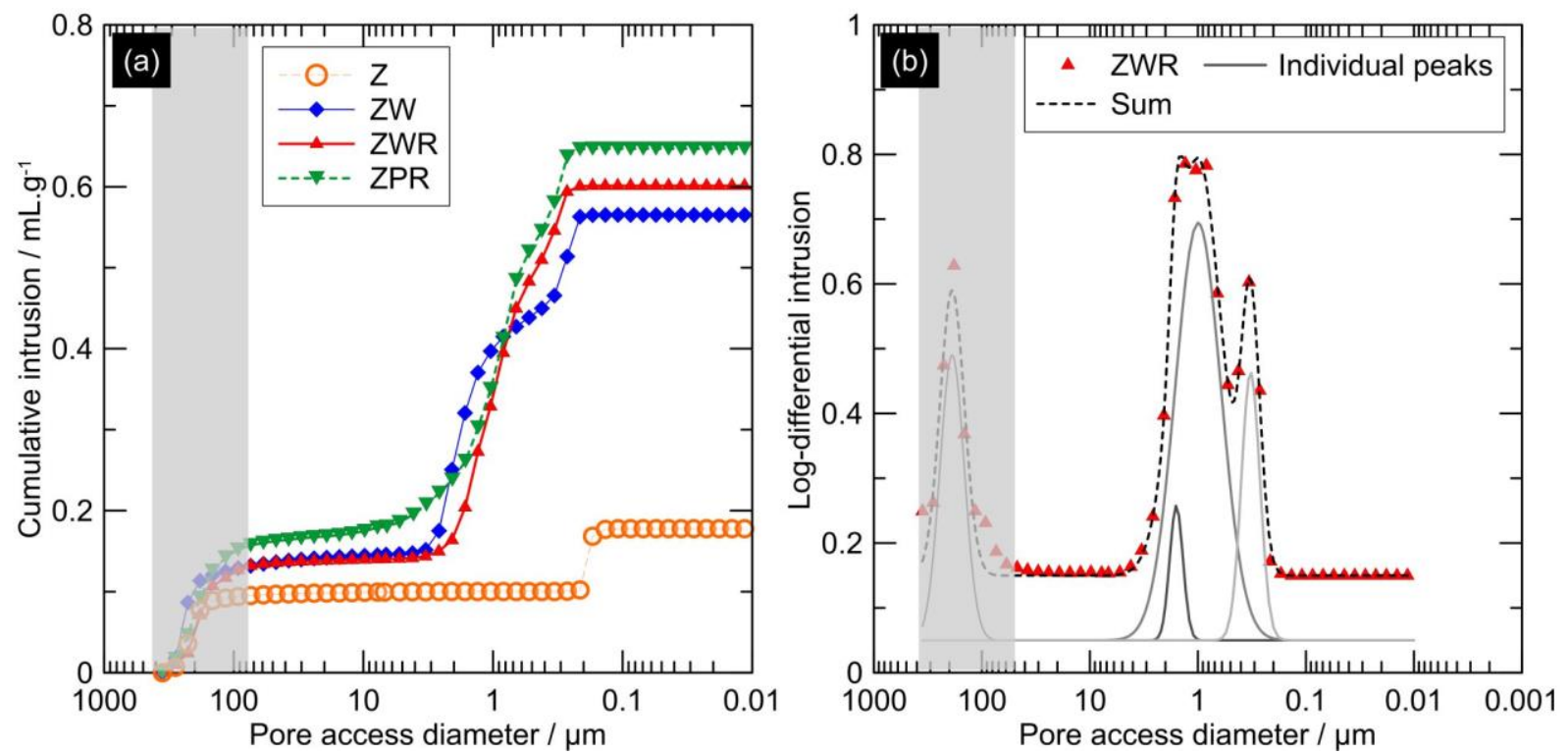

Figure 7: (a) Cumulative intrusion of mercury inside fabricated scaffolds; (b) Deconvolution of the log-differential intrusion curve into three families for ZWR (representing $\frac{d V}{d(\log (D))^{\prime}}$, V(intrusion volume) in $\mathrm{mL} \cdot \mathrm{g}^{-1}, \mathrm{D}$ (pore access diameter) in $\mu \mathrm{m}$ ). 
Table 2 summarizes the values of pores volumes and access diameters obtained by this deconvolution. For all compositions, sub-micronic pores kept with partial sintering are revealed by a last steep increase of the cumulative intrusion at around $0.3 \mu \mathrm{m}$. Measurements of the diameter of these submicronic pores by MIP is rather accurate due to their cylindrical capillary shape that suits the model behind the pressure - pore diameter correspondence in MIP.

Size and volume of macro-porosity were obtained by image analysis of tomography scans. Table 2 shows the apparent geometric density obtained for 5 samples of each composition, with their standard deviation and mean value. The apparent porosity can be deduced from those measurements. It has to be noticed that this apparent porosity is the porosity of the whole sample, including macro-porosity due to the design; whereas the total micro-porosity calculated with mercury intrusion porosimetry is only the porosity created in the filaments. Regarding the techniques used, results are consistent here between the apparent porosity and the sum of the total micro-porosity and the macro-porosity obtained by X-ray tomography.

\begin{tabular}{|c|c|c|c|c|c|c|c|c|}
\hline & & Composition & $\bar{Z}$ & $\mathrm{ZW}$ & $\overline{Z W R}$ & & $\overline{\mathrm{ZPR}}$ & \\
\hline \multirow{7}{*}{ 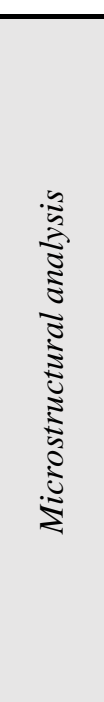 } & $\begin{array}{l}\text { Tomo Image } \\
\text { analysis }\end{array}$ & $\begin{array}{l}\text { Macroporosity } \\
(\text { Vol. \%) }\end{array}$ & $32 \pm 2$ & $18 \pm 2$ & $22 \pm$ & & $18 \pm$ & \\
\hline & \multirow{4}{*}{$\begin{array}{l}\text { Mercury Intrusion } \\
\text { Porosimetry }\end{array}$} & $\begin{array}{l}\text { Micronic, access } \\
\text { diameters }(\mu \mathrm{m})\end{array}$ & NA & $\mathrm{W}: 1.8$ & \multicolumn{2}{|c|}{$\mathrm{W}: 1.6$} & \multicolumn{2}{|c|}{ P: 3} \\
\hline & & $\begin{array}{l}\text { Micronic porosity } \\
\text { (Vol. \%) }\end{array}$ & 0 & W: 51 & $\left.\begin{array}{l}\mathrm{W}: 19 \\
\mathrm{R}: 32\end{array}\right]$ & 51 & $\begin{array}{l}\text { P: } 23 \\
\text { R: } 31\end{array}$ & 54 \\
\hline & & $\begin{array}{l}\text { Sub-micronic } \\
\text { pore diameter } \\
(\mu \mathrm{m})\end{array}$ & 0.2 & 0.2 & \multicolumn{2}{|l|}{0.3} & \multicolumn{2}{|c|}{0.3} \\
\hline & & $\begin{array}{l}\text { Sub-micronic } \\
\text { (Vol. \%) }\end{array}$ & 31 & 11 & \multicolumn{2}{|l|}{10} & \multicolumn{2}{|l|}{11} \\
\hline & $\begin{array}{l}\text { SEM Image } \\
\text { analysis }\end{array}$ & $\begin{array}{l}\text { Sub-micronic } \\
\text { (Vol. \%) }\end{array}$ & $33 \pm 2$ & $13 \pm 2$ & \multicolumn{2}{|c|}{$8 \pm 2$} & \multicolumn{2}{|c|}{$11 \pm 2$} \\
\hline & & $\begin{array}{l}\text { Total porosity } \\
\text { (Vol. \%) }\end{array}$ & $64 \pm 2$ & $80 \pm 2$ & \multicolumn{2}{|c|}{$83 \pm 2$} & \multicolumn{2}{|c|}{$\mathbf{8 3} \pm 2$} \\
\hline \multirow{2}{*}{ 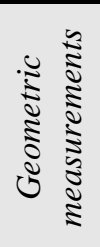 } & \multirow[t]{2}{*}{$\begin{array}{l}\text { Weight and } \\
\text { caliper gauge }\end{array}$} & $\begin{array}{l}\text { Apparent density } \\
\left(\mathrm{g} . \mathrm{cm}^{-3}\right)\end{array}$ & $2.14 \pm 0.12$ & $1.13 \pm 0.03$ & \multicolumn{2}{|c|}{$1.06 \pm 0.05$} & \multicolumn{2}{|c|}{$1.08 \pm 0.04$} \\
\hline & & $\begin{array}{l}\text { Apparent } \\
\text { porosity } \\
\text { (Vol. \%) }\end{array}$ & $\mathbf{6 5 . 8} \pm 1.8$ & $\mathbf{8 1 . 9} \pm 0.5$ & \multicolumn{2}{|c|}{$\mathbf{8 3 . 1} \pm 0.8$} & \multicolumn{2}{|c|}{$\mathbf{8 2 . 7} \pm 0.6$} \\
\hline
\end{tabular}

Table 2: Porosity and distribution of pores sizes by complementary techniques: total porosity deduced from apparent density, Image Analysis on tomography scans (IA-CT, for macro and micronic porosities) and SEM micrographs (IA-SEM for sub-micronic porosity), Mercury Intrusion porosimetry (MIP) (W: wheat; R: rice; P: potato).

\subsection{Mechanical properties}

\subsubsection{Compression test}

Figure 8(a) shows the stress-strain curves of $\mathrm{Z}$ scaffolds in compression. All curves are affected by local defects with several sharp stress drops during the loading phase, before final fracture. There is no observation of linear elastic domains and maximum compressive strength obtained range from 6 to $15 \mathrm{MPa}$. Figure $8(\mathrm{~b})$ shows the compressive behaviour of the scaffolds with addition of starches (ZW, ZWR, ZPR). All these samples show a typical cellular behaviour: after contact settling, a first linear part followed by an irregular plateau before fracture, with a limited standard deviation between fracture values. It is obvious here that the more porous the sample, the less resistant. Maximum compressive values obtained for those samples are quite low (from 0.19 MPa for ZPR to 0.40 MPa for $\mathrm{ZW})$. Moreover the material with only one family of micronic pores has a twice higher compressive strength than the ones with two families $\left(\sigma_{\mathrm{c}[\mathrm{ZPR}]}=0.19 \mathrm{MPa} \approx \sigma_{\mathrm{c}[\mathrm{ZWR}]}=0.23 \mathrm{MPa}<\right.$ 
$\left.\sigma_{\mathrm{c}[\mathrm{ZW}]}=0.40 \mathrm{MPa}\right)$ for a similar total porous fraction. There is no significant difference between ZPR and ZWR.

Table 3 shows that compressive strength show a limited scatter for porous samples, on the contrary, values are more scattered for $\mathrm{Z}$ composition with less porosity.
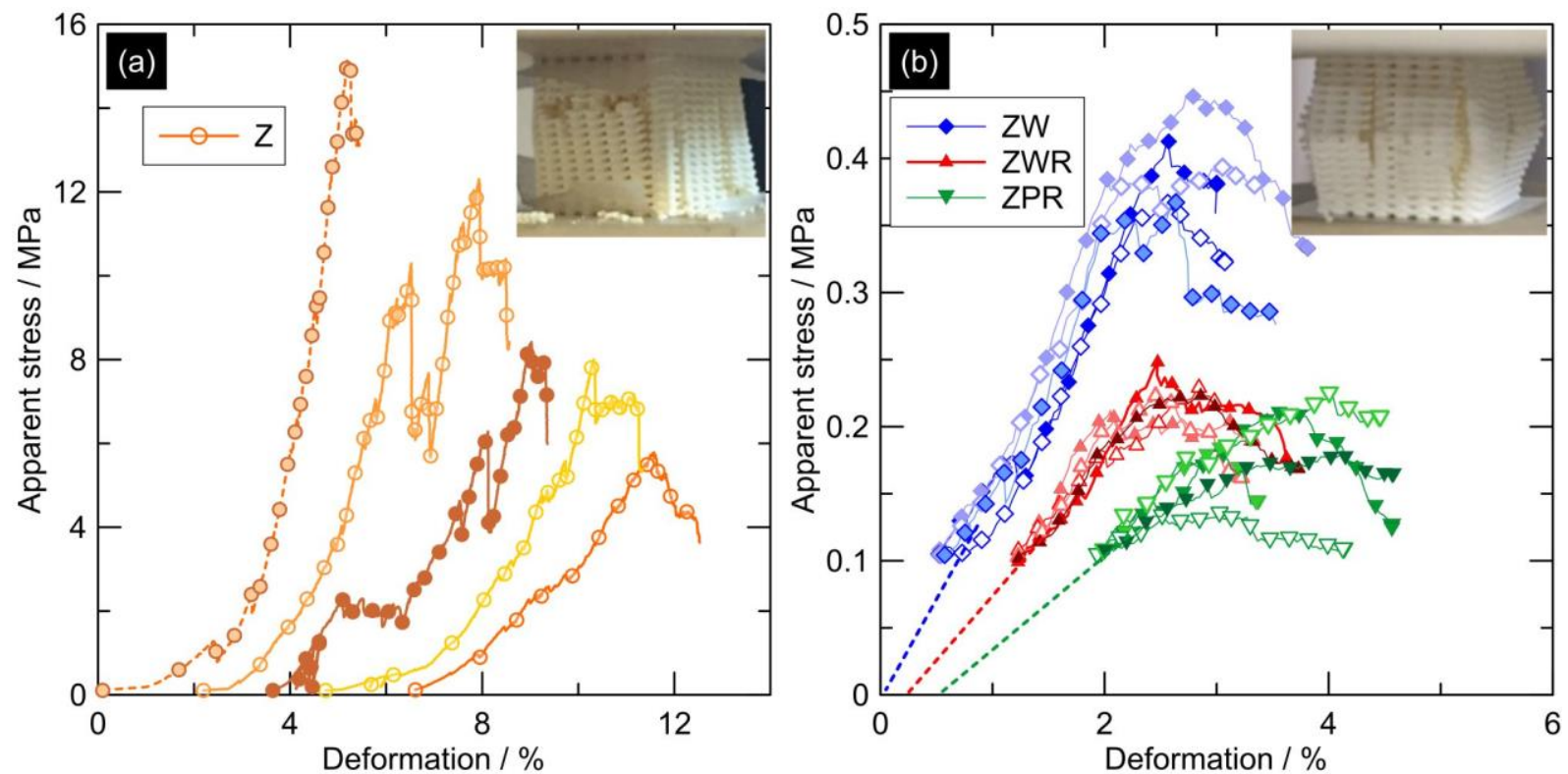

Figure 8: Mechanical properties of fabricated scaffolds in compression test. (a) For scaffold without porogen (individual curves were shifted in deformation for better reading); (b) For scaffold with porogen (groups of curves were shifted by $0.5 \%$ deformation for better reading). Inserts: picture of the sample after testing. The unloading curves are not represented. Dotted lines corresponds to the pre-load of the samples.

\begin{tabular}{ccc}
\hline & $\begin{array}{c}\boldsymbol{\sigma}_{c}: \text { Average } \pm \text { std dev } \\
(\mathbf{M P a})\end{array}$ & Std dev/average (\%) \\
\hline $\mathbf{Z}$ & $9.87 \pm 3.82$ & 39 \\
$\mathbf{Z W}$ & $0.40 \pm 0.03$ & 8 \\
$\mathbf{Z W R}$ & $0.23 \pm 0.01$ & 4 \\
$\mathbf{Z P R}$ & $0.19 \pm 0.03$ & 16 \\
\hline
\end{tabular}

Table 3: Maximum compressive strain $\left(\sigma_{c}\right)$ for each composition.

\subsubsection{Mechanical properties of the filaments}

Figure 9 shows the load/displacement curves for each composition during 3 points bending tests of individual filaments. They all show a purely linear, elastic, fragile behaviour up to fracture as expected. Table 4 summarizes the equivalent bending strength and Young's modulus values. The maximum strength value $\left(\sigma_{b}\right)$ supported by the samples is significantly higher for composition $\mathrm{Z}$ than from all others (from $1 \mathrm{MPa}$ for ZPR to $37.9 \mathrm{MPa}$ for $\mathrm{Z}$ ). In addition, bending strength is higher for the composition with only one family of starch added than for the two compositions with two families of starch added $\left(\sigma_{\mathrm{b}[\mathrm{ZW}]}=2.4 \mathrm{MPa}>\sigma_{\mathrm{b}[\mathrm{ZWR}]} \approx \sigma_{\mathrm{b}[\mathrm{ZPR}]} \approx 1 \mathrm{MPa}\right)$. Again there is no significant difference between ZPR and ZWR.

Young's modulus is higher for composition without starch addition than for all composition with $\operatorname{starch}\left(\mathrm{E}_{[\mathrm{Z}]}=6.9 \mathrm{GPa}>\mathrm{E}_{[\mathrm{ZW}]}=0.59 \mathrm{GPa}>\mathrm{E}_{[\mathrm{ZWR}, \mathrm{ZPR}]} \approx 0.25 \mathrm{GPa}\right)$. Among starch-containing materials, again the Young's modulus is twice higher in $\mathrm{ZW}$, whereas there is no difference between ZWR and ZPR.

To summarize, three groups of samples can be made: $Z$ materials possess the highest Young's modulus and strength. ZW properties are much lower, but still twice higher than those of ZWR and ZPR (that cannot be distinguished). 

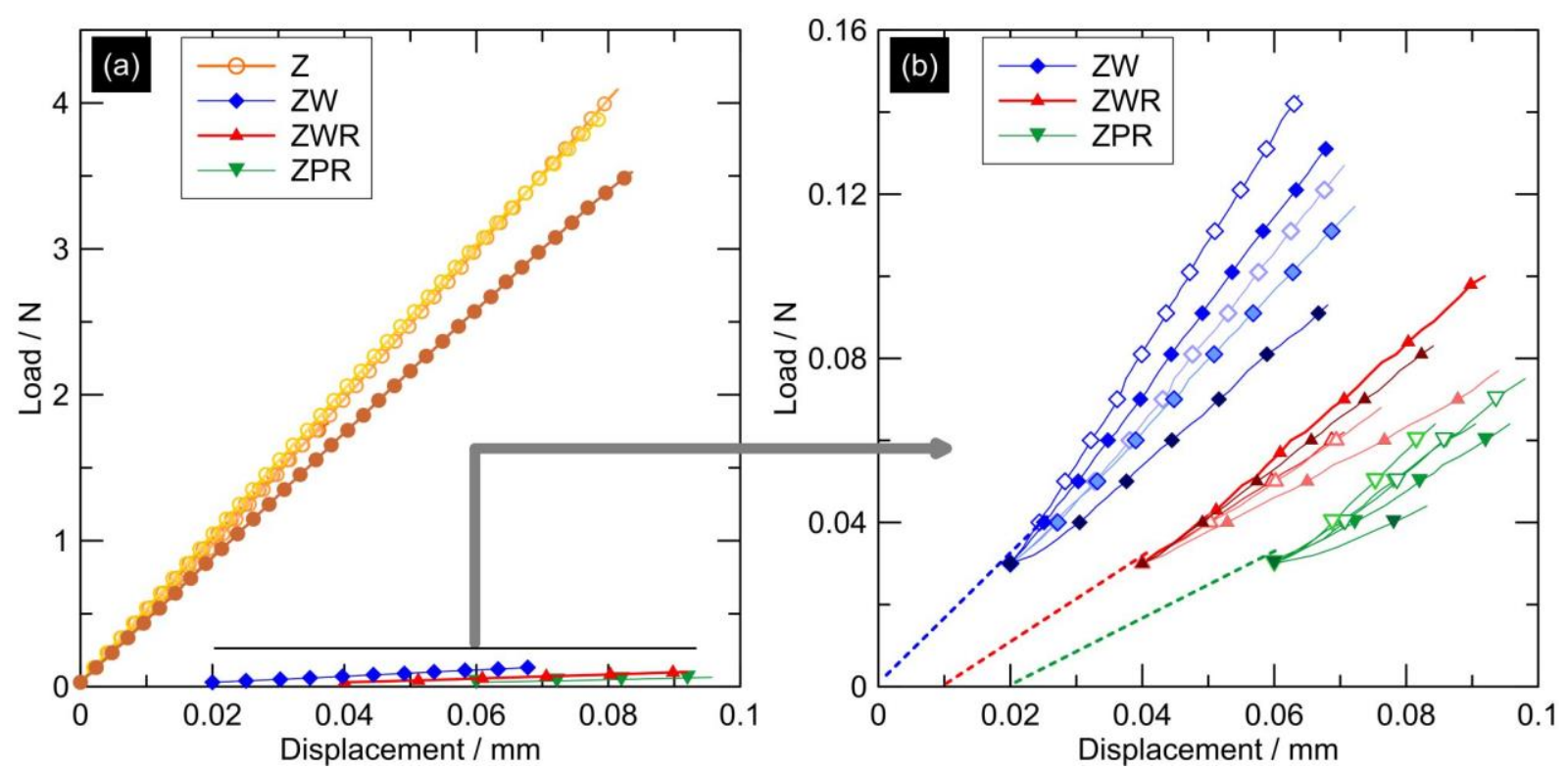

Figure 9: (a) Mechanical properties of printed filaments in 3 points bending tests; (b) Zoom of 9(a). Groups of curves are shifted in $x$ axis (by $0.01 \mathrm{~mm}$ each) for the sake of clarity.

\begin{tabular}{ccccc}
\hline $\begin{array}{c}\boldsymbol{\sigma} \text { b: } \text { Average } \pm \text { std } \\
\text { dev }(\mathbf{M P a})\end{array}$ & $\begin{array}{c}\text { Std dev/average } \\
(\boldsymbol{\%})\end{array}$ & Mean E (GPa) & $\begin{array}{c}\text { Std dev/average } \\
(\boldsymbol{\%})\end{array}$ \\
\hline $\mathbf{Z}$ & $37.9 \pm 13.7$ & 36 & $6.9 \pm 1.3$ & 19 \\
$\mathbf{Z W}$ & $2.4 \pm 0.4$ & 17 & $0.59 \pm 0.12$ & 20 \\
$\mathbf{Z W R}$ & $1.2 \pm 0.3$ & 25 & $0.25 \pm 0.04$ & 17 \\
$\mathbf{Z P R}$ & $1.0 \pm 0.2$ & 20 & $0.25 \pm 0.05$ & 22 \\
\hline
\end{tabular}

Table 4: Calculated apparent stress and Young's modulus for each composition.

\section{$\underline{\text { 4. Discussion }}$}

\subsection{Post-printing treatments}

To get intact samples after sintering, one needs to optimize all treatments performed after printing. The optimization process per se is not the topic of the present article. Nevertheless the main trends are presented here. The main issue is to avoid cracking at each step of the post-processing: drying, debinding, sintering.

During drying, the use of coconut oil as printing substrate was found to be efficient for minimizing the stresses between the printing support and the bottom of the printed pieces, coherently with existing literature [43]. Coconut oil contains lauric, myristic, and oleic acids. Its viscosity sharply decreases between printing temperature $\left(23^{\circ} \mathrm{C}\right.$ ) and drying temperature (up to $60^{\circ} \mathrm{C}$ ), due to the successive melting of lauric acid at around $45^{\circ} \mathrm{C}$ and myristic acid at around $59{ }^{\circ} \mathrm{C}$ (oleic acid is already liquid (above $\sim 13{ }^{\circ} \mathrm{C}$ ) which helps obtaining thin coating of coconut oil). Indeed printing is made on a semisolid, thin coconut oil layer, but as soon as the temperature is increased during the drying process the coconut oil layer becomes liquid, releasing the printed part from the substrate (all the more that these fatty acids are not soluble in water, thus there is no interdiffusion of the printed filaments and coconut oil layer) [44]. However, due to the semi-solid state of the coconut oil at $23{ }^{\circ} \mathrm{C}$, if too much is deposited on the printing substrate, the first layer of extruded filaments will not adhere to the substrate when printed, leading to printing issues. That is why only a thin layer of coconut oil deposited above a Teflon layer was found to be optimum to minimize the drying stresses without denaturing the printing.

During debinding, a very slow heating up to $350^{\circ} \mathrm{C}$ was necessary to remove all the PF127 and most of the starches without cracking the material (except ZW). Above this temperature no PF127 remained, and since gas resulting from the degradation of starches can escape through larger channels (the channels left by starches themselves), the heating ramp can be a bit higher without damaging the 
samples. Another way to decrease the risk of cracking during debinding would have been to decrease the organic content in the pastes. Indeed the use of PF127 results here in organic content as high as $\sim 25$ vol.\% in the $\mathrm{Z}$ material after drying. For example using a dispersant-binder-coagulant system [30,31] instead of PF127 to reach the right rheology would significantly reduce this inorganic content and ease its burning out.

Finally, the sintering step chosen here is slow enough not to risk cracking the samples. It was optimized (slow heating ramps and low temperature) to favour surface diffusion mechanisms that induce neck growth instead of densification. This induces a material consolidation without shrinkage so as to preserve both reasonable mechanical properties and a very porous structure (sub-micronic porosity).

\subsection{Effect of starch as porogen}

Starches are insoluble in water at room temperature, thus it is possible to incorporate them in the hydrogel-based formulations without changing their compositions, and to print them at room temperature. The use of starch as porogen is especially relevant for robocasting of porous ceramics scaffolds. The gelling and swelling of added starch powders by water uptake and their benefits for the integrity of the scaffolds during drying cannot be obviously excluded from the reasons why the scaffolds with added starch powders are less prone to crack formation. Indeed, the starch-containing materials present significantly reduced cracking (Figure 5) as compared to the reference $\mathrm{Z}$ material. This may be related to their gelling and swelling by water uptake between 55 and $80{ }^{\circ} \mathrm{C}$, that helps reducing the evaporation speed during drying and debinding steps, decreasing the occurrence of cracking in the scaffolds during these steps. This may also be due to the higher permeability of starchcontaining scaffolds to water diffusion, related to the presence of large, ceramic-free channels, and that may decrease the humidity gradients inside the materials. Moreover, the starch swelling may results in a decrease of water content in the rest of the paste. Thus ceramic particles are brought up closer together, consolidating the green bodies [22, 25] (which is one of the bases of starch consolidation process). This may partly explains the larger number of cracks observed in $\mathrm{Z}$ materials, that do not benefit from starch consolidation and may also suffer from a lower permeability to water diffusion. Unfortunately, one becomes without knowing how much this factor accounts for, as the extent at which the starch consolidation has effectively occurred during our drying process. In the present work the starch-consolidating phenomenon is not exploited to its maximum, since drying has already occurred to a certain degree when the materials reach $55-60^{\circ} \mathrm{C}$, starting point of starches gelling. With this in mind, the drying process could be further optimized by keeping a high water partial pressure up to $80^{\circ} \mathrm{C}$, thus ensuring more efficient swelling and gelling of the starch, and then slowly decreasing the water partial pressure to induce the drying of the samples. Moreover, a temperature of $80^{\circ} \mathrm{C}$ would be just below the temperature at which a large viscosity decrease of the PF17 gels occurs (above $\sim 82^{\circ} \mathrm{C}$ for $25 \mathrm{wt} \%$ PF127 gels) [45,46]. As a result, the drying cycle used here does not fully exploit the starch consolidation effect, but the cracks observed on the $\mathrm{Z}$ material (that does not benefit from the starch consolidation) show that this mechanism is (partially) active. Finally, when swelling with the increase in temperature, starch deforms to sickle cell-shape, as revealed by SEM (Figure 4(h,l,p)) and local X-ray tomography characterizations (Figure 5(j-l)). This may enhance the tortuosity of the porous network created during their elimination. The larger diameter of the filaments measured by image analysis on tomography scans for compositions ZW, ZWR and ZPR (Figure 4(b,f,j,n) and Figure 6) could be a consequence of the starch swelling during the drying step. Largest filament diameter was measured for the ZPR composition with the use of potato starch. This is coherent with previous results showing that swelling is more important for potato starch than wheat or rice starch due to a higher water uptake caused by a larger proportion of amylopectin/amylose in its composition [3].

The starch to ceramic particle volume ratio is usually smaller than $1 / 1$ for processes involving starch as porogen since a ratio of $0.6 / 1$ is sufficient to create interconnected porosity [24,47]. However, results obtained in the present study reveal that starches can be used in larger amount (volume ratio of $2 / 1$ ), even for complex processes like robocasting, to create highly porous materials. Nevertheless, 
the fabrication process has to be carefully controlled in particular in order to disperse starch particles that tend to agglomerates, leading to the formation of big pores thus of critical defects.

\subsection{Rheological behaviour of the pastes}

Rheological behaviour of the PF127 network is hardly changed with increasing solids loading (Figure 3 ), which validates the role of carrier of PF127, as already highlighted in previous work [48].

Generally, the addition of loads in a PF127 matrix leads to a viscosity increase [11]. As zirconia particles size is much smaller than starch particles, the surface area exposed to the liquid phase is increased, the zirconia to zirconia particles contact are more numerous, and the viscosity is higher when the zirconia load is higher, as it is the case for $\mathrm{Z}$ composition. The presence of rice starch (the smallest one, around $3 \mu \mathrm{m}$ in diameter) in paste with two starches families, may also explain why the pastes ZPR and ZWR show a higher viscosity and storage modulus than paste with only wheat starch (ZW) (Figure 3(c,d)). Such an increase in the viscosity with the addition of small solid loads was already observed in starch consolidating process [22].

A local apparent collapse of the structure could be more or less observed on Figure 4(b,f,j,n) depending of the paste formulation. This apparent collapse can be explained in two ways:

- The mean filaments diameter is bigger for pastes containing starch as compared to zirconia alone because the filaments have swelled due to the presence of the starch (Figure 6), thus reducing the interfilament spacing.

- The stiffness of the pastes just after extrusion is low $(\sim 100 \mathrm{~Pa})$, which causes a slight sag of the filaments between two crossings of filaments on two successive layers.

The most apparent collapse might be observed for the scaffold shown in Figure 4(f), derived from ZW ink. Different factors such as solids loading, particle size and particle size distribution, density of the particles, types and concentrations of the processing additives, etc., all concur to the stiffness of the pastes. Furthermore, others factors like kinetics of the storage modulus recovery after extrusion (measured here to be less than 18s in ZW, as seen in Figure 3(g), stresses/deformations imposed by printing a new layer over the already deposited layers, spans between the supporting filaments also influence the possibility to observe collapse.

However, the observed filaments cross sections are always well cylindrical and no clear macroscopic collapse of the structure (defined as a deformation of the structure under its own weight or the capillary forces between struts) could be characterized. From the measurement of the external dimensions of the structures, the macroscopic collapse would be shown by the thickness being more decreased than the lateral dimensions (relatively to the numerical model); that was not clearly evidenced in this study, where we measured lateral shrinkage of $27 \pm 1 \%$ and height shrinkage of 32 $\pm 5 \%$.

\subsection{Multi-scale porosity}

Figure 10 sums up the porous fraction of the samples fabricated with different types of pores: macroscopic, micronic and sub-micronic. The fraction and average size of each type of porosity show the complexity of the micro-porosity created with the developed process.

Characterization of the micro-porosity with mercury intrusion technique suffers from some limitations. In fact, pores left by starches have tortuous shape and the filament surfaces are rough due to the high quantity of porosity and/or the presence of cracks. All of this can lead to an improper determination of the intrusion diameter of the pores (indeed, this technique measure the pore access diameters, not the diameter of the pores themselves), but the global pores volume is correct. However, this technique was relevant for the comparison of the different compositions fabricated here.

In addition, the use of several characterization techniques (apparent density measurements, image analysis (IA) on tomography scans for macro-porosity and on SEM micrographs for sub-micronic porosity, mercury intrusion porosimetry (MIP) technique for micronic and sub-micronic porosity) was necessary to generalize our findings on the different populations of pores created in each composition. Results are summarized in Table 2 and are consistent between each technique. Scaffolds 
with around $85 \%$ of total porosity were fabricated with the addition of starch, which really highlights the interest of the combination of several techniques to fabricate highly porous ceramic scaffolds. In fact, with robocasting technique, it is difficult to create porous material with porosity higher than $70 \%$. Moreover, it has to be noted here that the quantity of each type of porosity can be easily chosen depending on the specification of the application by simply working on design, paste composition or on heat treatment parameters.

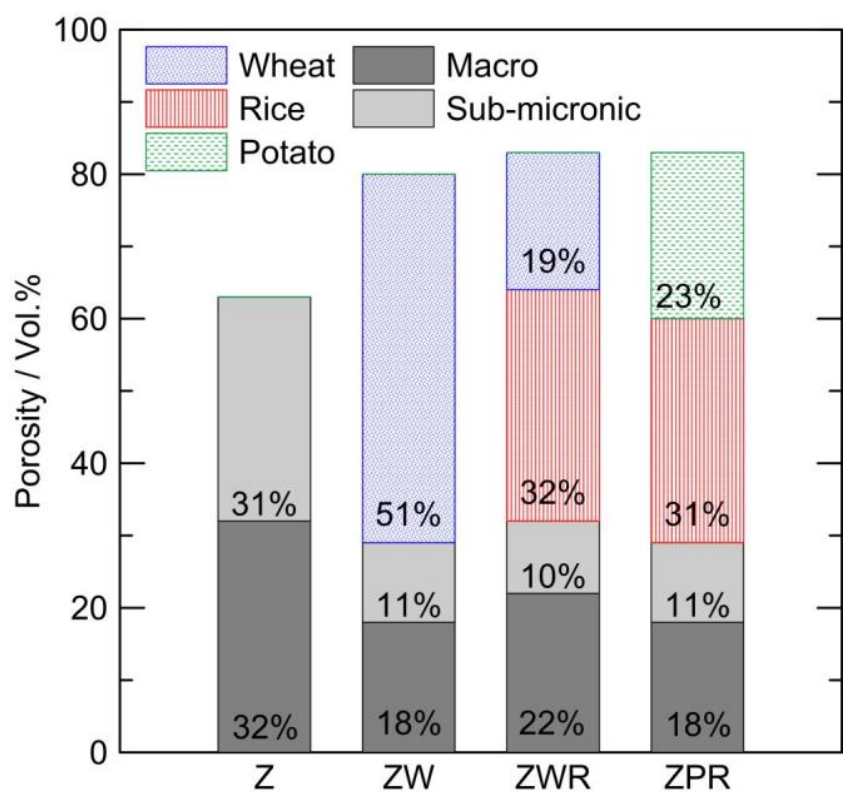

Figure 10: Distribution of the overall created porosity at different scale for fabricated parts.

\subsection{Effect of the porosity on mechanical properties}

\subsubsection{Fracture mechanisms}

All samples showed a linear elastic behaviour in bending with a brittle fracture. Mechanical behaviour of each composition seems consistent between the compressive results and the 3 points bending results. All compositions with addition of starch show weaker fracture stress compared to composition $\mathrm{Z}$. The increase in porosity decreases mechanical strength, and tend to generate damage in compression, consistently with previous studies [49]. At the same total porosity, for the compositions with micronic porosity, a strong influence of the starch composition is noted with a twice lower maximum stress for compositions with two populations of starch, both in compressive tests and in 3 points bending tests (Table 3 and Table 4) as compared to composition ZW. This could be explained by the resulting heterogeneity in pores sizes and shapes. Indeed, X-ray tomography and SEM characterization (Figure 4(j,n) and Figure 5) highlighted the random distribution of the two distinct populations of pores, left by potato and rice starches, and by wheat and rice starches for compositions ZPR and ZWR respectively. The largest pores, distributed heterogeneously in the struts, could be assimilated to critical defects that initiate cracks under load. It is difficult to conclude on the effect of the size and shape of the pores on mechanical properties since strength of ZPR and ZWR are in the same range of values in compression and in bending tests.

Almost no materials with comparable architecture and composition could be found in the literature. No Ce-stabilized zirconia were ever printed by robocasting. A few Ce-TZP/Al $\mathrm{O}_{3}$ composites were tested [50,51] and, in addition to the intrinsically higher strength of Ce-TZP/Alumina composites, always with much higher density, leading to better strength (up to $300 \mathrm{MPa}$ for $38 \%$ porosity). Robocast structures with porous struts are also seldom characterized $[18,52]$, but usually show better strength (1 to $10 \mathrm{MPa}$ ) than what was obtained here, probably due to smaller and more homogeneous pore size inside the struts. Finally, other works on similar structures made of yttria-stabilized zirconia are compiled in [53], and show also better strength, due to non-porous struts and the presence of phase transformation toughening (inhibited in our materials by the small grain size). To summarize, the 
strength obtained here are large enough for the envisioned application, but do not compare to the best materials from this point of view.

\subsubsection{Monofilament testing}

The diameter of the filaments used for the 3 points bending tests $(\sim 800 \mu \mathrm{m})$ is supposed to be equivalent for the comparison with the filaments diameter of the scaffolds $(\sim 400 \mu \mathrm{m})$, even if the fracture stress may be a bit affected by the sample size.

To evaluate the consistency of the two mechanical tests, compression and flexion, maximum compressive stress $\left(\sigma_{c}\right)$ and maximum 3 points bending stress $\left(\sigma_{b}\right)$ were compared using GibsonAshby analysis that leads to the expressions of the collapse strengths for brittle fracture of open-cell foams:

$\frac{\sigma_{c}}{\sigma_{b}} \propto C \cdot\left(\frac{\rho}{\rho_{f}}\right)^{\frac{3}{2}}$

where $\rho / \rho_{\mathrm{f}}$ is the relative density of the part (relative to the density of the filament), $\sigma_{c}$ is the maximum stress in compression, $\sigma_{b}$ is the maximum stress in tension and $\mathrm{C}$ is a constant [54]. Table 5 shows the values of the constant $\mathrm{C}$ obtained for each composition for $\sigma_{\mathrm{b}}$ and $\sigma_{\mathrm{c}}$ determined experimentally, comprised between 1.3 and 1.9. The disparity in the constant $\mathrm{C}$ values between $\mathrm{C}_{[\mathrm{Z}]}$ on one hand and $\mathrm{C}_{[\mathrm{ZW}],[\mathrm{ZWR}] \text {, [ZPR] }}$ on the other hand, may be explained by the weak reproducibility in compression and in bending for $\mathrm{Z}$ composition. Additional values of $\rho / \rho_{\mathrm{f}}$ (and different macroporosity) are necessary to check if the fracture of the scaffolds follow the Gibson-Ashby law. Still, from this analysis, it seems that 3 points bending test of a monofilament is a good indicator of the performances of the whole printed parts in compression. The trends observed between bending on single filament and compression tests in scaffolds are very close for each composition, even in the evolution of the dispersion of the measured values (Table 3 and Table 4). Therefore, using 3 points bending on single filaments seems robust enough for a first investigation of the mechanical properties of new formulations. Indeed, the method used to produce single filaments is easier and faster than the fabrication of centimetric parts. Moreover, the evaluation of the Young's modulus is more accurate and statistical analysis of both the Young's modulus and the mechanical strength could be made using 3 points bending of single filaments. Obviously, the interactions between two successive layers of 3D parts are then not taken into consideration and have to be investigated through compressive tests to thoroughly characterize the mechanical properties of the robocasted parts. Finally, one can conclude from these results that the compressive fracture of the sample is mainly governed by the fracture of the constitutive filaments.

\begin{tabular}{|c|c|c|c|c|}
\hline & $\mathbf{Z}$ & $\mathbf{Z W}$ & ZWR & ZPR \\
\hline$\left(\sigma_{c} / \sigma_{b}\right)$ & 0.26 & 0.17 & 0.19 & 0.19 \\
\hline$\rho / \rho_{f}$ & 0.5 & 0.46 & 0.45 & 0.50 \\
\hline$(\rho / \rho f)^{3 / 2}$ & 0.35 & 0.32 & 0.30 & 0.36 \\
\hline C & 1.3 & 1.9 & 1.7 & 1.9 \\
\hline
\end{tabular}

Regarding compression tests (Figure 8), even though precautions were taken (optimization of the printing substrate and use of parafilm layer), tests are difficult to implement and to analyze due to the limited elastic domain, due to early damage in the contact zone between sample and loading platens. Implementation of such tests can be improved by preparation of the sample (wax impregnation of the sample top and bottom surfaces), as it is the case in previous work [55]. However, in this work, mechanical compressive behaviour of the as-printed samples were of interest. To further improve the description of the fracture in compression, finite element modelling coupled with in-situ X-ray tomography could be preferred, beyond the scope of this study.

Lastly, the main interest of such porous structures is their versatility. It is possible to easily adapt the process to a specific application [7] by working on its parameters, to answer both macro-scopic 
specificities such as the design of the structure, and the micronic and sub-micronic scales in order to adapt the porous characteristics at microscopic level such as pores sizes and shapes, or the pores interconnectivity level. Therefore, the main strength of this process is the possibility to hierarchize the porosity from the macroscopic scale to the sub-micronic scale in order to answer a specific application. To go further, it could be interesting to fabricate complex shape pieces with such complex micro-porous networks. In this direction, fabrication of tubular porous filament by coextrusion is currently investigated in our laboratory, to seek for microstructure similar to the ones obtained in previous work [ㄷ6].

As presented in [7], this material is very efficient to act as support material for hygroscopic salts for thermochemical heat storage and exchange applications: the salts penetrate the porosity network, and can exchange water vapour with the exterior medium. As the hydration of salts is exothermic, this is a way to store and release heat (thermochemical energy storage), with most obvious potential applications in buildings (inter-seasonal heat storage for instance).

\section{Conclusion}

In summary, water-based ceramic pastes containing ceria-stabilized-zirconia and starches of different natures were developed and printed with robocasting technique. Highly porous zirconia scaffolds of around $85 \%$ of porosity were fabricated. Those scaffolds show a hierarchized, interconnected porosity at three different scales thanks to the developed fabrication process. This multi-scale porosity was achieved through the combination of macroscopic design allowed by the additive fabrication technique, of starch addition as sacrificial fugitives and of partial sintering of the robocasted scaffolds. It was highlighted in this study that tunable porosity can be obtained by using different types of starches or by combining them. Even though the starch consolidating-technique enables the fabrication of crack-free highly porous scaffolds, their resultant mechanical properties strongly decrease when added in large quantity. Monofilament testing in bending appears as an efficient method to estimate the mechanical properties of a whole scaffold. To go further and to give more functionality, it could be interesting to evaluate the feasibility of samples printed with complex structure and microstructure, as well as to increase the sample size by a factor of two or three in order to evaluate the robustness of the fabrication process.

\section{Acknowledgements}

This work is part of DECARTH project, supported by the French national research agency (ANR, France) [grant number ANR-16-CE22-0006].

\section{$\underline{\text { References }}$}

[1] M. Scheffler, P. Colombo, Cellular Ceramics: Structure, Manufacturing, Properties and Applications, 2006. https://doi.org/10.1002/3527606696.

[2] S. Cassiano-Gaspar, D. Bazer-Bachi, J. Chevalier, E. Lécolier, Y. Jorand, L. Rouleau, Novel extrudates based on the multiscale packing of alumina particles and boehmite or aluminophosphate binders, Powder Technol. 255 (2014) 74-79. https://doi.org/10.1016/j.powtec.2013.09.019.

[3] T.T. Dele-Afolabi, M.A.A. Hanim, M. Norkhairunnisa, S. Sobri, R. Calin, Research trend in the development of macroporous ceramic components by pore forming additives from natural organic matters: A short review, Ceram. Int. 43 (2016) 1633-1649. https://doi.org/10.1016/j.ceramint.2016.10.177.

[4] M. Černý, Z. Chlup, A. Strachota, J. Svítilová, J. Schweigstillová, M. Halasová, Š. Rýglová, Si-O-C ceramic foams derived from polymethylphenylsiloxane precursor with starch as foaming agent, J. Eur. Ceram. Soc. 35 (2015) 3427-3436. https://doi.org/10.1016/j.jeurceramsoc.2015.04.032.

[5] R. Detsch, S. Schaefer, U. Deisinger, G. Ziegler, H. Seitz, B. Leukers, In vitro: osteoclastic activity studies on surfaces of 3D printed calcium phosphate scaffolds., J. Biomater. Appl. 26 (2011) 359-380. https://doi.org/10.1177/0885328210373285.

[6] E. Saiz, L. Gremillard, G. Menendez, P. Miranda, K. Gryn, A.P. Tomsia, Preparation of porous hydroxyapatite 
scaffolds, Mater. Sci. Eng. C. 27 (2007). https://doi.org/10.1016/j.msec.2006.05.038.

[7] L. Tabard, E. Prud'Homme, V. Garnier, L. Gremillard, Hierarchical Salt-Ceramic Composites for Efficient Thermochemical Energy Storage., Appl. Mater. Today $20 \quad$ (2020) 100658. https://doi.org/10.1016/j.apmt.2020.100658

[8] S. Deville, Freeze-casting of porous ceramics: A review of current achievements and issues, Adv. Eng. Mater. 10 (2008) 155-169. https://doi.org/10.1002/adem.200700270.

[9] Z. Chen, Z. Li, J. Li, C. Liu, C. Lao, Y. Fu, C. Liu, Y. Li, P. Wang, Y. He, 3D printing of ceramics: A review, J. Eur. Ceram. Soc. 39 (2019) 661-687. https://doi.org/10.1016/j.jeurceramsoc.2018.11.013.

[10] A. Zocca, P. Colombo, C.M. Gomes, J. Günster, Additive Manufacturing of Ceramics: Issues, Potentialities, and Opportunities, J. Am. Ceram. Soc. 98 (2015) 1983-2001. https://doi.org/10.1111/jace.13700.

[11] E. Feilden, Additive Manufacturing of Ceramics and Ceramic Composites via Robocasting, Imperial college London, 2017.

[12] J. Barberi, F. Baino, E. Fiume, G. Orlygsson, A. Nommeots-Nomm, J. Massera, E. Verné, Robocasting of SiO2Based Bioactive Glass Scaffolds with Porosity Gradient for Bone Regeneration and Potential Load-Bearing Applications, Materials 12 (2019) 2691. https://doi.org/10.3390/ma12172691

[13] B. Nan, P. Golebiewski, R. Buczynski, F. J. Galindo-Rosales, J. M. F. Ferreira, Direct Ink Writing Glass: A Preliminary Step for Optical Application, Materials 13 (2020) 1636. https://doi.org/10.3390/ma13071636

[14] Q. Fu, E. Saiz, M.N. Rahaman, A.P. Tomsia, Bioactive glass scaffolds for bone tissue engineering: State of the art and future perspectives. Mater. Sci. Eng. C 31 (2011) 1245-1256

[15] L.C. Hwa, S. Rajoo, A.M. Noor, N. Ahmad, M.B. Uday, Recent advances in 3D printing of porous ceramics: A review, Curr. Opin. Solid State Mater. Sci. 21 (2017) 323-347. https://doi.org/10.1016/j.cossms.2017.08.002.

[16] U.G.K. Wegst, H. Bai, E. Saiz, A.P. Tomsia, R.O. Ritchie, Bioinspired structural materials, Nat. Mater. 14 (2015) 23-36. https://doi.org/10.1038/nmat4089.

[17] E. Juste, Elaboration de réacteurs catalytiques membranaires à microstructures et architectures contrôlées, Université de Limoges, 2008.

[18] C. Minas, D. Carnelli, E. Tervoort, A.R. Studart, 3D Printing of Emulsions and Foams into Hierarchical Porous Ceramics, Adv. Mater. 28 (2016) 9993-9999. https://doi.org/10.1002/adma.201603390.

[19] S. S. L. Chan, M. L. Sesso, G. V. Franks, Direct ink writing of hierarchical porous alumina-stabilized emulsions: Rheology and printability, J Am Ceram Soc. 103 (2020) 5554-5566. https://doi.org/10.1111/jace.17305

[20] E. Munch, J. Franco, S. Deville, P. Hunger, E. Saiz, A.P. Tomsia, Porous ceramic scaffolds with complex architectures, JOM. 60 (2008) 54-58. https://doi.org/10.1007/s11837-008-0072-5.

[21] A. Ortona, C. D’Angelo, S. Gianella, D. Gaia, Cellular ceramics produced by rapid prototyping and replication, Mater. Lett. 80 (2012) 95-98. https://doi.org/10.1016/j.matlet.2012.04.050.

[22] O. Lyckfeldt, J.M.F. Ferreira, Processing of porous ceramics by 'starch consolidation,' J. Eur. Ceram. Soc. 18 (2002) 131-140. https://doi.org/10.1016/s0955-2219(97)00101-5.

[23] K. Prabhakaran, A. Melkeri, N.M. Gokhale, S.C. Sharma, Preparation of macroporous alumina ceramics using wheat particles as gelling and pore forming agent, Ceram. Int. 33 (2007) 77-81. https://doi.org/10.1016/j.ceramint.2005.07.020.

[24] M.L. Sandoval, M.H. Talou, A.G. Tomba Martinez, M.A. Camerucci, E. Gregorová, W. Pabst, Starch Consolidation Casting of Cordierite Precursor Mixtures - Rheological Behavior and Green Body Properties, J. Am. Ceram. Soc. 98 (2015) 3014-3021. https://doi.org/10.1111/jace.13719.

[25] L. M .Rodríguez-Lorenzo, M. Vallet-Regí, J. M. F. Ferreira, Fabrication of porous hydroxyapatite bodies by a new direct consolidation method: starch consolidation, J. Biomed. Mater. Res. 60 (2) (2002) 232-40. https://doi.org/10.1002/jbm.10036

[26] C. C. Furnas, The Relation between Specific Volume, Voids and Size Composition in Systems of Broken Solids of Mixed Sizes, Bur. Mines, Rep. Invest. (1928) 2894

[27] C. Chang, R.L. Powell, Effect of particle size distributions on the rheology of concentrated bimodal suspensions, J. Rheol. 38 (1994) 85-98. https://doi.org/10.1122/1.550497.

[28] M.J. Jivan, M. Yarmand, A. Madadlou, Preparation of cold water-soluble potato starch and its characterization, J. Food Sci. Technol. 51 (2014) 601-605. https://doi.org/10.1007/s13197-013-1200-y.

[29] Y.J. Choi, M.Y. Baik, B.Y. Kim, Characteristics of granular cold-water-soluble potato starch treated with alcohol and alkali, Food Sci. Biotechnol. 26 (2017) 1263-1270. https://doi.org/10.1007/s10068-017-0172-5.

[30] D. Brazete, A. S. Neto, J. M. F. Ferreira, Optimization of zirconia inks to fabricate 3D porous scaffolds by robocasting, Lekar a technika - Clinician and Technology 49(1) (2019) 5-10.

[31] B. Nan, F. J. Galindo-Rosales, J.M.F. Ferreira, 3D printing vertically: Direct ink writing free-standing pillar arrays, Materials Today 35 (2020) 16-24 https://doi.org/10.1016/j.mattod.2020.01.003

[32] S. Michna, W. Wu, J.A.Lewis. Concentrated hydroxyapatite inks for direct-write assembly of 3-D periodic scaffolds, Biomaterials 26(28) (2005) 5632-9. https://doi.org/10.1016/j.biomaterials.2005.02.040

[33] J.E.Smay, J. Cesarano, J.A. Lewis. Colloidal inks for directed assembly of 3-D periodic structures, Langmuir. 2002;18(14): 5429-37. https://doi.org/10.1021/la0257135

[34] J. Franco, P. Hunger, M.E. Launey, A.P. Tomsia, E. Saiz. Direct write assembly of calcium phosphate scaffolds using a water-based hydrogel, Acta Biomater. 2010;6(1):218-28. https://doi.org/10.1016/j.actbio.2009.06.031

[35] E. Feilden, E. B. Garcia-Tuñon, F. Giuliani F, E. Saiz, L. Vandeperre. Robocasting of Structural Ceramic Parts with 
Hydrogel Inks, J. Eur. Ceram. Soc. 2016;36:2525-33. https://doi.org/10.1016/j.jeurceramsoc.2016.03.001

[36] E.-J. Courtial, C. Perrinet, A. Colly, D. Mariot, J.-M. Frances, R. Fulchiron, C. Marquette, Silicone rheological behavior modification for 3D printing: evaluation of yield stress impact on printed object properties, Addit. Manuf. 28 (2019) 50-57. https://doi.org/10.1016/j.addma.2019.04.006.

[37] J. Barthes, E.-J. Courtial, E. Brenet, C.B. Muller, H. Knopf-Marques, C. Marquette, N.E. Vrana, Using 3-D Printing and Bioprinting Technologies for Personalized Implants, in: Adv. Biomech. Tissue Regen., Elsevier, 2019: pp. 269-286. https://doi.org/10.1016/B978-0-12-816390-0.00014-5.

[38] T.A. Instrument, Rheology Solutions:Determining the Linear Viscoelastic Region in Polymers, n.d. http://www.tainstruments.com/pdf/literature/RS23.pdf.

[39] W. David Kingery, H. K. Bowen, D. R. Uhlmann, Introduction to ceramics, 2nd edition (chapter 10), Wiley Interscience, 1976. ISBN-13: 978-0471478607

[40] T. Hildebrand, P. Rüegsegger, A new method for the model-independent assessment of thickness in threedimensional images, J. Microsc. 185 (2015) 67-75. https://doi.org/10.1046/j.1365-2818.1997.1340694.x.

[41] T. Saito, J. Toriwaki, New algorithms for euclidean distance transformation of an n-dimensional digitized picture with applications, Pattern Recognit. 27 (1994) 1551-1565. https://doi.org/10.1016/0031-3203(94)90133-3

[42] N. Wang, E. Maire, Y. Cheng, Y. Amani, Y. Li, J. Adrien, X. Chen, Comparison of aluminium foams prepared by different methods using X-ray tomography, Mater. Charact. 138 (2018) $296-307$. https://doi.org/10.1016/j.matchar.2018.02.015.

[43] E. Peng, X. Wei, U. Garbe, D. Yu, E. Brunet, A. Liu, J. Ding, Robocasting of dense yttria-stabilized zirconia structures, J. Mater. Sci. 53 (2018) 247-273. https://doi.org/10.1007/s10853-017-1491-X.

[44] N.H. Jayadas, K.P. Nair, Coconut oil as base oil for industrial lubricants-evaluation and modification of thermal, oxidative and low temperature properties, Tribol. Int. $39 \quad$ (2006) 873-878. https://doi.org/10.1016/j.triboint.2005.06.006.

[45] B. Shriky, A. Kelly, M. Isreb, M. Babenko, N. Mahmoudi, S. Rogers, O. Shebanova, T. Snow, T. Gough, Pluronic F127 thermosensitive injectable smart hydrogels for controlled drug delivery system development, Journal of Colloid and Interface Science 565 (2020) 119-130. https://doi.org/10.1016/j.jcis.2019.12.096

[46] S. Y. Park, Y. Lee, K. H. Bae, C.-H. Ahn, T. G. Park, Temperature/pH-Sensitive Hydrogels Prepared from Pluronic Copolymers End-Capped with Carboxylic Acid Groups via an Oligolactide Spacer, Macromolecular Rapid Communications 28 (2007) 1172-76. https://doi.org/10.1002/marc.200600914.

[47] S. Ghosh, J.C. Viana, R.L. Reis, J.F. Mano, The double porogen approach as a new technique for the fabrication of interconnected poly(L-lactic acid) and starch based biodegradable scaffolds, J. Mater. Sci. Mater. Med. 18 (2007) 185-193. https://doi.org/10.1007/s10856-006-0680-y.

[48] E. Feilden, E. García-Tuñón Blanca, F. Giuliani, E. Saiz, L. Vandeperre, Robocasting of structural ceramic parts with hydrogel inks, J. Eur. Ceram. Soc. $36 \quad$ (2016) 2525-2533. https://doi.org/10.1016/j.jeurceramsoc.2016.03.001.

[49] S. Meille, M. Lombardi, J. Chevalier, L. Montanaro, Mechanical properties of porous ceramics in compression: On the transition between elastic, brittle, and cellular behavior, J. Eur. Ceram. Soc. 32 (2012) 3959-3967. https://doi.org/10.1016/j.jeurceramsoc.2012.05.006.

[50] L. Goyos-Ball, E. García-Tuñón, E. Fernández-García, R. Díaz, A. Fernández, C. Prado, E. Saiz, R. Torrecillas,Mechanical and biological evaluation of 3D printed 10CeTZP-Al2O3 structures, J. Eur. Ceram. Soc. 37 (9) (2017) 3151-3158, https://doi.org/10.1016/j.jeurceramsoc.2017.03.012.

[51] J. Chevalier, A. Liens, H. Reveron, F. Zhang, P. Reynaud, T. Douillard, L. Preiss, V. Sergo, V. Lughi, M. Swain, N. Courtois, Forty years after the promise of "Ceramic steel?": Zirconia-based composites with a metal-like mechanical behavior, J. Am. Ceram. Soc. 103 (3) (2020) 1482-1513. https://doi-org/10.1111/jace.16903

[52] J. Cesarano III, J. G. Dellinger, M. P. Saavedra, D. D. Gill, R. D. Jamison, B. A. Grosser, J. M. Sinn-Hanlon, M. S. Goldwasser, Customization of Load-Bearing Hydroxyapatite Lattice Scaffolds, Int. J. Appl. Ceram. Technol. 2 [3] (2005) 212-220

[53] J. Liu, B. Ren, Y. Lu, Y. Rong, C. Wang, L. Wang, J. Yang, Y. Huang, Mechanically robust ZrO2 foams with 3D reticular architecture prepared from chemical-modified $\mathrm{ZrO} 2$ powder, J Am Ceram Soc. In press (2020). https://doi.org/10.1111/jace.17120

[54] L.J. Gibson, M.F. Ashby, Cellular Solids, Cambridge University Press, 1997. https://doi.org/10.1017/CBO9781139878326.

[55] C. Petit, S. Meille, E. Maire, L. Gremillard, J. Adrien, G.Y. Lau, A.P. Tomsia, Fracture behavior of robocast HA/ $\beta$-TCP scaffolds studied by X-ray tomography and finite element modeling, J. Eur. Ceram. Soc. 37 (2017) 1735-1745. https://doi.org/10.1016/j.jeurceramsoc.2016.11.035.

[56] T. Li, D. Zhai, B. Ma, J. Xue, P. Zhao, J. Chang, M. Gelinsky, C. Wu, 3D Printing of Hot Dog-Like Biomaterials with Hierarchical Architecture and Distinct Bioactivity, Adv. Sci. 6 (2019) 1901146. https://doi.org/10.1002/advs.201901146. 